\title{
University satellite institutes as exogenous facilitators of technology transfer ecosystem development
}

\author{
Marcus Conlé ${ }^{1,2}$ (D) $\cdot$ Henning Kroll ${ }^{3,4}$ (D) $\cdot$ Cornelia Storz ${ }^{5}$ (D) Tobias ten Brink $^{1}$ (i)
}

Accepted: 17 November 2021 / Published online: 5 December 2021

(c) The Author(s) 2021

\begin{abstract}
Universities can contribute to knowledge-based regional development not only in their home region but also in other regions. In a number of countries, universities have established university satellite institutes in additional (host) regions to promote research and technology transfer there. We investigate the role of university satellite institutes in the industrial development of regions, which, albeit not economically marginal, suffer from a weak knowledge infrastructure, limited absorptive capacities for external knowledge in the business sector and hence a low degree of attractiveness for non-local knowledge actors. Despite policy recommendations in favor of establishing satellite institutes, there has only been limited empirical research on this phenomenon, particularly concerning technology transfer ecosystem development. To fill this gap, we provide an exploratory case study of university satellite institutes in the Pearl River Delta of China's Guangdong province. We show how such institutes can be successful in facilitating the development of their host region's technology transfer ecosystems and demonstrate why they should be conceptually included in our existing understanding of third mission activities. Our research centers on the interplay of geographical proximity and non-spatial, organized proximity in the development of interregional knowledge bridges and entrepreneurial opportunities. We argue that the university's geographical proximity is only successful if the satellite institute, by facilitating organized proximity, promotes the geographical proximity of further knowledge actors, hereby propelling ecosystem development.
\end{abstract}

Keywords China $\cdot$ University technology transfer $\cdot$ Ecosystems $\cdot$ Innovation intermediaries $\cdot$ Peripheral regions

JEL Classification I23 $\cdot \mathrm{I} 28 \cdot \mathrm{L} 26 \cdot \mathrm{O} 3 \cdot \mathrm{R} 12 \cdot \mathrm{R} 58$

Marcus Conlé

m.conle@jacobs-university.de

Extended author information available on the last page of the article 


\section{Introduction}

This paper contributes to the literature on universities as a driver of regional knowledgebased development by exploring the particular phenomenon of university satellite institutes in China. Previous research has established that universities can play a central role in regional development via a great variety of third mission activities (Etzkowitz et al., 2000; Gibbons et al., 1994). Such activities range from qualification over multiple well-known technology transfer channels (Bozeman, 2000; Link et al., 2015; Siegel et al., 2003) and concrete interactions with firms (Perkmann et al., 2013; Petruzelli, 2011) to involvement in local change agency (Benneworth \& Fitjar, 2019). While policymakers at different levels frequently seek to leverage this development potential, universities with strong third mission capacities have transformed into innovation hubs (Youtie \& Shapira, 2008) and orchestrators of "technology transfer ecosystems" (Good et al., 2020; Heaton et al., 2019).

So far, these processes have almost exclusively been considered with a view to the universities' contribution to stimulating growth, innovation and socio-economic renewal within their home regions. As has increasingly become clear, however, their impact may also reach well beyond their immediate environment (Kolesnikov et al., 2019). In a number of countries, universities have begun to actively access other regions by establishing specific, purpose-bound subsidiaries. In addition to satellite (or branch) campuses, which tend to duplicate the activities of their parent universities on a smaller scale (Charles, 2016; Rossi \& Goglio, 2020), such intermediaries include university satellite institutes that cater to the development goals of their host region by focusing more narrowly on research and technology transfer (Almeida et al., 2011; Isaksen \& Trippl, 2017).

In this paper, we will empirically explore the functioning as well as the local embedding of such purpose-bound university satellite institutes in Guangdong, China, where they were explicitly set up to rebalance an overly business-driven transfer ecosystem. We will show how such institutes can be successful in promoting regional development, particularly in knowledge-peripheral regions, and demonstrate why they should be conceptually included in our existing understanding of third mission activities.

Conceptually, out-of-home-region activities can be justified by the expectation that colocation will induce knowledge spillovers and innovation opportunities (Asheim \& Gertler, 2005; Malmberg \& Maskell, 2006). For some time, innovation policy recommendations have included suggestions to relocate knowledge-generating institutions closer to those that may use and/or commercialize it (Etzkowitz \& Klofsten, 2005; Tödtling \& Trippl, 2005). However, the experiences of many such regions have been disappointing (Bonaccorsi, 2017; Brown, 2016), demonstrating that without the parallel development of non-spatial, organized forms of proximity, the establishment of geographical proximity through colocation will merely be of limited use as a catalyst for regional innovation (Crescenzi et al., 2017). Whether and how university satellite institutes create and utilize such proximity will depend on how successful they are in transforming dyadic, transactional interactions into a larger, systemic web of organized proximity involving regional and extra-regional interactions. As the recent literature on university technology transfer ecosystems (Audretsch et al., 2019; Good et al., 2020; Nieth et al., 2018) proposes, the nature and effectiveness of knowledge transfer hinges on proximity constellations among a collection of relevant ecosystem actors rather than individual proximity combinations (Villani et al., 2017; Yamamura \& Lasalle, 2020).

Despite the increasing relevance of university satellite institutes, there exists only limited empirical knowledge on the nature of their technology transfer ecosystems, the 
relations between geographical and organized forms of proximity in the satellite institute's ecosystem development, the knowledge and complementary resource flows involved, and the ways in which the institutes contribute to regional innovation. This study aims to fill this gap by exploring the structure, activities, and interactions of the institutes' technology transfer ecosystems and the essential proximity relations in detail. We employ a qualitative case study design, involving an in-depth study of a single university satellite institute case, supplemented by two (literal) replication cases to corroborate and refine our findings (Yin, 2018).

In addition to advancing knowledge on university technology transfer in China (Chen et al., 2016), our research extends the recent interest on university technology transfer ecosystems to the issue of non-local universities as an exogenous source of ecosystem development, especially in knowledge-peripheral regions. We particularly highlight the specific role of university satellite institutes in propelling ecosystem dynamics by encouraging the geographical proximity of further non-local knowledge actors-including technology firms, university researchers, and innovation teams - in techno-industrial sectors targeted by the host region. By so doing, we contribute a dynamic perspective on proximity relations in university-industry knowledge transfer. We argue that the success in promoting regional techno-industrial development depends on the capacity of the geographically proximate satellite institutes for creating organized proximities that generate additional permanent and temporal geographical proximity.

The paper is structured as follows: Sect. 2 provides the theoretical background. The research context and methodological approach are described in Sect. 3. Section 4 presents the findings. We conceptualize and explain the university satellite institute's technology transfer strategy (Sect. 4.1) and clarify the relevant proximity relations and associated innovation resource flows (Sect. 4.2). We discuss our findings in Sect. 5. Section 6 concludes.

\section{Theoretical background}

\subsection{Technology transfer ecosystems}

The rise of the knowledge-based economy has increased the university's salience as a knowledge producer, while knowledge transfer has become a strategic concern for national and regional economic development (Etzkowitz et al., 2000; Geuna \& Muscio, 2009; Gibbons et al., 1994). Universities are expected to become "territorial actors" (Lawton Smith, 2003) and, together with government and industry, construct regional advantage (Cooke \& Leydesdorff, 2006) by anchoring global knowledge to create local innovation "buzz" (Benneworth \& Hospers, 2007), and, more generally, by developing into innovation-promoting knowledge hubs (Youtie \& Shapira, 2008).

The widespread regional focus notwithstanding, geographical proximity is yet not generally necessary for successful university-industry interaction. Firms with significant R\&D intensity and absorptive capacity tend to search for academic partners independent of the university's location (De Fuentes \& Dutrénit, 2016). They prefer university research quality to geographical proximity (Laursen et al., 2011), even if they keep ties to regional universities for the sake of contributing to the local community (Fitjar \& Gjelsvik, 2018). Nonetheless, there is broad agreement that geographical proximity facilitates industry-university interaction (D’Este et al., 2013; Fritsch \& Aamoucke, 2013). Geographical proximity is especially relevant for the launch of academic startups and spinoffs (Calcagnini 
et al., 2016), technological cooperation with engineering-based firms that operate in sectors with a high share of synthetic knowledge (Steinmo \& Rasmussen, 2016), and the support of SMEs with low absorptive capacity and weak in-house R\&D capabilities (Grillitsch \& Nilsson, 2015). Moreover, geographical proximity facilitates interaction during various stages and activities of the innovation process. It is comparatively more relevant for development rather than research activities (Davids \& Frenken, 2018), for incremental innovation (Stojcic, 2021), and for the generation of close-to-the-market ideas due to the improved access to industry-specific knowledge (Asheim \& Coenen, 2006; Tanner, 2018).

Despite the advantages, universities have often played a disappointing role in regional development (Bonaccorsi, 2017; Brown, 2016). A pivotal problem is that successful knowledge transfer and innovation frequently requires a combination of resources, knowledge spillovers, local endowments, and government support (Audretsch et al., 2019). Concentrating on individual interactions between university and firm can therefore be too narrow a focus. Recent literature considers interactions between university and industry in their ecosystem contexts, centering on the entrepreneurial university's "generative" role, which concerns startup formation and the colocation of new firms (Gunasekara, 2006). Ecosystems organize resources around technology transfer opportunities (Cao \& Shi, 2020). There is a strong relationship between ecosystem characteristics and the way resources are drawn from the environment (Good et al., 2020; Spigel, 2017). In terms of structural characteristics, the ecosystem perspective builds on regional innovation system approaches analyzing university-industry links "in the context of territorially embedded networks of firms, universities and other organizations" (Uyarra, 2010: 1237) and regional "triple helix" interactions (Heaton et al., 2019; Ranga \& Etzkowitz, 2013). Considering the university as a loosely coupled system, some ecosystem perspectives elaborate on interactions among the universities' various academic departments and entrepreneurship support structures. The research particularly highlights the role of specialized intermediaries established by, or in cooperation with, universities and/or university staff (Hayter et al., 2018; Wright et al., 2017; Yusuf, 2008). ${ }^{1}$ Another strand focuses on entrepreneurship as a "local event" (Malecki, 2018), considering the universities' interactions with their regional environments. The latter research thus particularly highlights the role of local actors and stakeholders, including government agencies, investors, and other relevant actors, in developing regional technology transfer ecosystems (Fuster et al., 2019; Nieth et al., 2018; Yamamura \& Lasalle, 2020).

While many sources of ecosystem dynamics are endogenous to the region, the location of non-local knowledge actors can add momentum by providing access to exogenous resources and capabilities. This is especially relevant for "knowledge-peripheral" regions, where local, self-reinforcing development and innovation dynamics may be limited due to a paucity of local knowledge actors and a generally poor endowment with research, education, and business support organizations (Zukauskaite et al., 2017). Studies highlight the role of non-local knowledge actors in overcoming organizational thinness and regional lock-in, and in creating new industrial development paths particularly in those

\footnotetext{
1 The literature draws on previous research on specialized individual intermediaries, including technology transfer offices (Bercovitz et al., 2001; Brescia et al., 2016; Siegel et al., 2003), science parks (Lecluyse et al., 2019), and technology business incubators (Lamine et al., 2018). Components of university technology transfer also comprise research-based intermediaries such as the industry-university cooperative research centers in the United States (Adams et al., 2001; Shapira 2001) or Germany's university “associate research institutes" (Koschatzky and Stahlecker 2010).
} 
knowledge-peripheral regions (Trippl et al., 2018). Above all, universities can be important in this regard due to their global-local connecting role (Benneworth \& Hospers, 2007). Policy recommendations therefore center on attracting non-local universities (or research and technology organizations) to these regions, in addition to establishing new knowledge institutions (Tödtling \& Trippl, 2005). Until recently, the literature on technology transfer ecosystems has concentrated on local universities in metropolitan settings, overlooking ecosystem dynamics in resource-scarce regions (Harima et al., 2021). With the exception of Isaksen and Trippl (2017), few have so far examined non-local universities as an exogenous source of ecosystem development in organizationally thin environments, and there are no studies so far for the particular case in which the university's host region is strong and dynamic economically, although it is poorly endowed with knowledge organizations.

\subsection{University satellite institutes}

Establishing a university presence within regions that lack a good knowledge infrastructure bears the potential to support technology transfer activities that thrive on geographical proximity, including technology entrepreneurship and knowledge commercialization. While founding wholly new universities takes a lot of time and resources, involving nonlocal universities can serve as a possibly more goal-oriented shortcut. In this case, an established university from another (usually metropolitan) region sets up a purpose-bound subsidiary to promote knowledge-based development and satisfy the demand for innovation capacity building within the (knowledge-peripheral) host region-which does not have to be an economically marginal region to have such a demand (Lagendijk \& Lorentzen, 2007). Such subsidiaries include not only university satellite campuses with their relatively strong focus on education (Charles, 2016; Rossi \& Goglio, 2020) but also, as the focal point of our paper, university research institutes (or ventures) from elsewhere within or outside the country, which are an increasingly important—-though understudied—phenomenon (Isaksen \& Trippl, 2017; Kolesnikov et al., 2019).

Successful satellite research institutes and campuses serve as "regional development catalyst", as "knowledge-mobilizing institutions" that link "the tacit and local knowledge held by different actors in a region with opportunities and knowledge from further afield" (Allison \& Eversole, 2008: 103, comma omitted). However, to achieve this outcome, they need to overcome several structural challenges relating to their emergent technology transfer ecosystems. Because of their intermediary functions, university satellite subsidiaries bear many similarities with "external" university intermediaries, which, contrary to internal intermediaries, have a higher organizational autonomy and/or are physically located outside the parent university (Brescia et al., 2016; Wright et al., 2008). University satellite subsidiaries yet need to be understood as a special kind of external intermediaries. Their defining characteristic is the physical location outside the parent university's home region-with likely repercussions for ecosystem structure, interactions, and resource flows. In recent ecosystem studies, the parent university is mostly considered a regional ecosystem hub that sets up and, in successful cases, orchestrates various intermediaries of the same region-mostly small, networked units located on or near campus performing specialized transfer functions-to realize technology transfer objectives (Good et al., 2020; Heaton et al., 2019; Wright et al., 2017). The satellite institute's spatial isolation from its parent university, on the other hand, requires it to take on the more central role of an ecosystem facilitator within the host region. 
Compared to the units of the parent university's home-region ecosystem, and in relation to their expected role, satellite institutes and campuses tend to face stronger resource and capability constraints. First, despite their limited scale and scope (Charles, 2016; Rossi \& Goglio, 2020), the satellite subsidiaries are typically less specialized as intermediaries in the parent university's home region. Especially satellite campuses face broad expectations, with tensions between local educational and industrial interests (Charles, 2016). Satellite research institutes are not quite as much exposed to this problem but still typically have to integrate a wider range of research and technology transfer functions, albeit related to quite specific regional techno-industrial development goals. Second, the peripherality of their host regions means that the satellite institutes and campuses cannot access external resources and capabilities with the same ease as the institutes and intermediaries located in the well-endowed parent-university home regions. They might be more reliant on local funding agencies to fund innovation projects related to the host region's economies (Rossi $\&$ Goglio, 2020) and more dependent on mobilizing resources from non-local actors (Eder, 2019), including the parent university. How to overcome these constraints, stemming from the parent university's "geographical diversification" (Rossi \& Goglio, 2020), and develop a successful technology transfer ecosystem is an important question that has not yet been addressed sufficiently in the literature, particularly with a view to satellite (research) institutes.

\subsection{Proximity relations in ecosystem development}

Ecosystem development requires the creation and maintenance of interactive ties among relevant actors as well as the alignment of their roles and functions. Technology transfer success "depends on the interconnectivity of [the transfer ecosystem's] constituent elements and their collective ability to provide information and resources" (Hayter et al., 2018: 1040). Proximity is relevant in this regard, as it facilitates connectivity, coordination, and interaction and is thus pivotal for the sharing, exchange, and transfer of knowledge and complementary innovation resources (Oerlemans et al. 2001). Importantly, proximity does not necessarily refer to spatial colocation (Torre \& Gilly, 2000). In addition to geographical proximity, defined solely in spatial terms-like the physical distance of two units (Torre $\&$ Rallet, 2005), the literature highlights organized forms of proximity, covering various relational dimensions. ${ }^{2}$ As we will demonstrate, the interplay between organized and geographical proximity is of particular relevance for understanding the role of university satellite institutes in the development of localized technology transfer ecosystems.

Following Torre and Rallet (2005), we decide to subsume different relational aspects under the term 'organized proximity', which results from being subject and/or having access to the same "set of routines—explicit or implicit—which allows coordination without having to define beforehand how to do so" (Knoben \& Oerlemans, 2006; Rallet \& Torre, 1999). Organized proximity pertains to common resemblance (similitude of cognitive frames, habits, norms, and practices) or common affiliation (to an organization, community, network, polity, for instance) (Carrincazeaux et al., 2008). The concept thus connects to both, institutional frameworks and organizational structures.

\footnotetext{
2 Several authors have compiled taxonomies of proximity dimensions ranging from five (Boschma 2005) to seven (Harmaakorpi et al., 2011) or more dimensions. Knoben and Oerlemans (2006) point out the conceptual ambiguity and overlap between the various non-spatial proximity dimensions and the problems of such broad taxonomies specifically for producing and comparing case studies.
} 
As "a method for understanding or analyzing innovation at the local level" (Carrincazeaux \& Coris, 2011: 271), the proximity approach arguably provides a good starting point for exploring university satellite institutes and their respective technology transfer systems. Setting up a university satellite institute involves changes of geographical proximity that have ramifications for related proximity dynamics and for resource provision and access. While, on the one hand, the establishment of a satellite institute entails an increase of geographical proximity to the targeted host location's economy, it concerns a decrease of geographical proximity to the parent university and its (metropolitan) home region. Whether, and how, this movement in geographical space benefits technology transfer and the regional economy depends on the impact of the locational choice on the generation and use of innovation resources resulting from the emerging proximity constellations (Yamamura \& Lasalle, 2020).

Based on the proximity literature, we can disentangle four distinct kinds of proximity relations that might be relevant for technology transfer via university satellite institutes. First, geographical proximity might constitute an individual source of direct knowledge flows. Moving to the host region might be associated with "geographically mediated knowledge spillovers" (Feldman, 1999), resulting from "neighborhood effects" (Malmberg \& Maskell, 2006). As Breschi and Lissoni (2001) emphasize, a clear distinction is to be made in this regard between "pure" knowledge spillovers, linked to the controversial issue of knowledge acquisition by simply "being there" (Fitjar \& Rodríguez-Pose, 2017), and pecuniary externalities, involving knowledge diffusion through regional labor and commodity markets. In the case of satellite institutes, the particular regional setting will likely affect the scale and scope of the spillovers. Second, geographical proximity might facilitate, and overlap with, organized proximity (Boschma, 2005; Hansen, 2015). It might thus be indirectly associated with the flows of knowledge and complementary resources from organized proximity. Organized proximity can either result automatically from colocation (Malmberg \& Maskell, 2006), which puts actors within a similar regional governance structure or other institutional frameworks (Cooke et al., 1997), or require the intermediary's "strategic agency" (Benneworth et al., 2017) to jointly develop organizational and institutional environments. In this sense, the central idea behind satellite institutes is that they may help to establish and create additional dynamics within regional ecosystems by building on geographical proximity to forge organized proximity to local ecosystem actors. At the same time, they are expected to establish organized proximity to nonlocal knowledge actors. In this regard, third, organized proximity might substitute for geographical proximity (Hansen, 2015; Menzel, 2015), bridging the physical distance to non-local actors (Menzel, 2015), especially to the parent university, to ensure access to relevant innovation resources. Fourth, organized proximity might facilitate geographical proximity-permanently or temporarily (Torre \& Rallet, 2005). We assume (cf. Rossi \& Goglio, 2020) that organized proximity to local actors might help university satellite institutes to develop a 'platform' function that raises the host region's attractiveness for inward flows of innovation resources, while it supports the region in anchoring and diffusing technological knowledge.

How these distinct dynamics play out in the context of university satellite institutes and their contribution to the development of technology transfer ecosystems, resource acquisition, and innovation will be explored in the subsequent empirical sections. 


\section{Methodology}

\subsection{Research context}

Interregional university technology transfer is an important element of China's innovation policy. While China's coastal economies have grown tremendously based on laborintensive manufacturing, many major manufacturing regions lack a well-developed knowledge infrastructure. To improve the situation, local governments have not only sought to attract multinational corporations but increasingly also non-local academic institutions to foster technology transfer. Kolesnikov et al. (2019) show that China is by far the main destination for international university research ventures by top US research universities. The establishment of international co-operations yet pales in comparison to the foundation of domestic university satellite intermediaries. The latter are particularly relevant in China's manufacturing regions.

Guangdong province is a pioneer and frontrunner in this regard. As China's most populous province (113.5 m inhabitants) with an area that roughly corresponds to the size of US state Missouri or half the size of Germany, it is organized into 21 regions, covering countylevel urban and rural areas each of which is administered by a prefecture-level city. Nine of them form the Pearl River Delta, the province's economic heartland, which is widely known as the "factory of the world". Outside the provincial capital Guangzhou, which has historically been home to a number of major universities, most prefectural regions have inherited a weak academic infrastructure. While this holds true for most Chinese provinces, it has different consequences in Guangdong, where the province's rise has prompted the emergence of further centers like Shenzhen that have come to eclipse Guangzhou in terms of innovative dynamics.

The province has prioritized the establishment of particular satellite intermediariesapplied research institutes by non-local universities. The history of these university satellite institutes can be divided into three periods. Starting in the late 1990s, Shenzhen, then a knowledge-peripheral city with virtually no universities and public research institutes, joined forces with academic institutions from Beijing and neighboring Hong Kong to establish the first satellite institutes. These early experiments were widened with the promulgation of the Plan on Developing Industry-University Linkages in Guangdong for the Period 2007-2011 jointly launched by the provincial government and the national-level Ministry of Education, which oversees China's most prestigious universities. This second period constitutes the peak phase of university satellite institute development, involving the diffusion of satellite institutes into further cities of the Pearl River Delta-most notably Dongguan and Foshan. Finally, the most recent period (2012-2017), associated with the Chinese government's push for innovation-driven development, has seen a further strengthening of university satellite institutes as a sub-group of so-called "New R\&D Institutes" (xinxing yanfa jigou; Conlé et al., 2021).

Figure 1 shows the home and host region of the 46 university satellite institutes that we can identify based on Guangdong's New R\&D Institute policy. ${ }^{3}$ Provincial capital Guangzhou is the home region of almost half of university institutes. Hong Kong is also a major

\footnotetext{
3 Application for New R\&D Institute policy status is open to all university satellite institutes. Among the 244 institutes that have successfully applied for the status in the years 2015-2018, and are officially listed, 50 institutes identify themselves as being university-related. Four of them are not satellite institutes according to our definition, however, as both their home and host region is Guangzhou.
} 


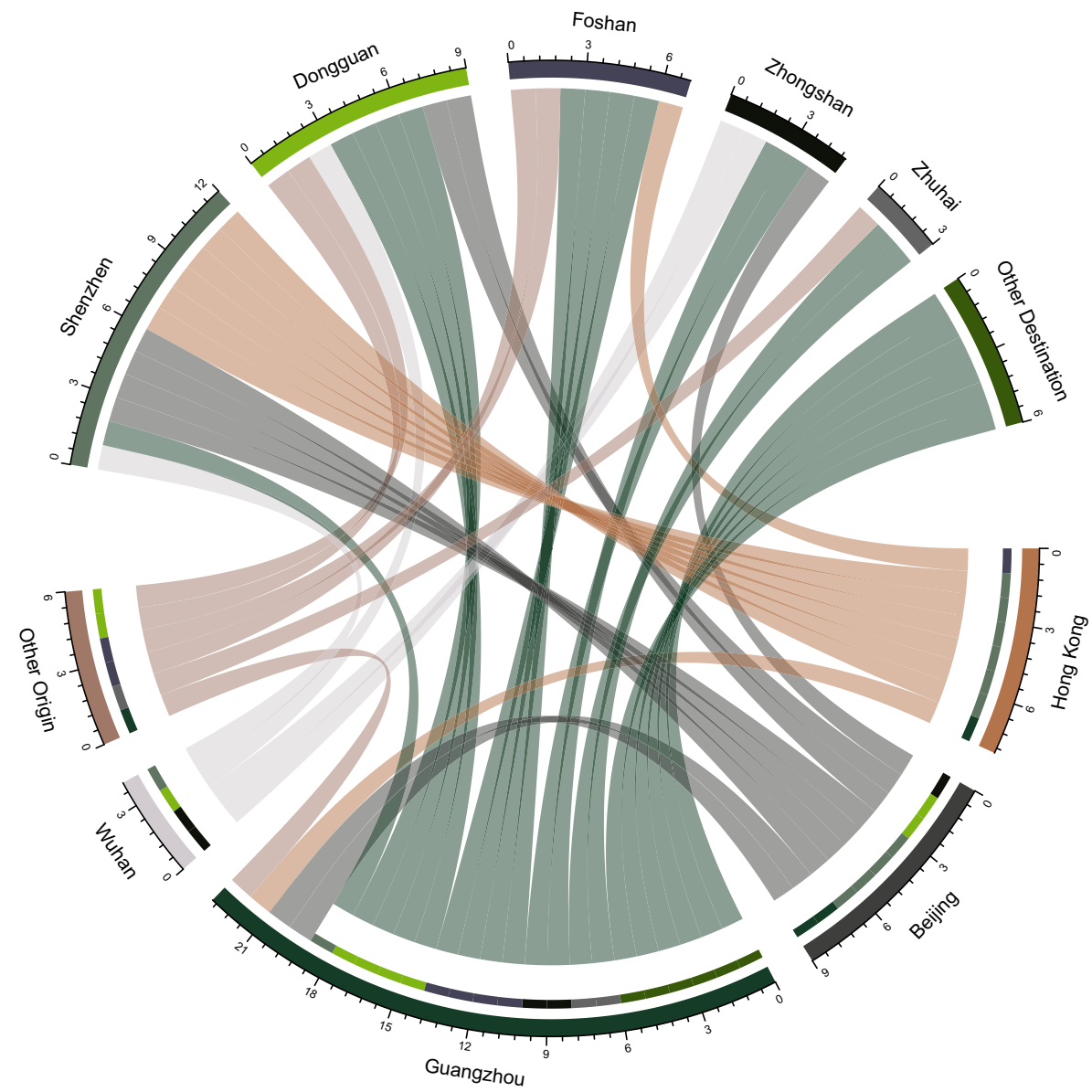

Fig. 1 University satellite institutes: Home and host regions. Note: Home regions at the bottom, host regions at the top of the chord diagram (created in $\mathrm{R}$ with "circlize" package)

source of satellite institutes, especially for Shenzhen. ${ }^{4}$ Several universities are from even further afar, including from Beijing and Wuhan, which have been joined more recently by other cities from the Yangtze River Delta. On the receiving end, all of the Pearl River Delta cities, except Jiangmen, had established university satellite institutes until 2017, and so had two regions outside the Pearl River Delta-Shaoguan and Heyuan. Shenzhen, Dongguan, and Foshan are the three most prolific cities in terms of university institute development.

\footnotetext{
4 The impact of Hong Kong universities on knowledge-based development in Guangdong is a question that is interesting in its own right (Conlé et al., 2021). To eschew problems of "dual embeddedness", concerning pressures on branch campuses or research ventures by varying home and host region institutional contexts (Shams \& Huisman, 2016), we focus on satellite institutes of mainland China universities only.
} 


\subsection{Case selection}

In Guangdong, policy support for university satellite institutes has become one of the major focal points of the province's innovation policy (Zeng et al., 2018). Several such institutes, all of them located in the Pearl River Delta, have fared particularly well in terms of technology commercialization. We have selected three of them to explore the proximity constellations and their related technology transfer strategies in more detail. To account for the potential relevance of further contextual conditions for transfer outcomes, the three selected cases vary by the parent university's home region, the satellite institute's host region, and the period of institute establishment. For want of a comprehensive source of comparable data, we relied on a variety of sources for our selection. We searched the China National Knowledge Infrastructure (CNKI) database, the largest academic journal database in China, for Chinese-language articles on individual university satellite institutes. We did the same concerning patent information contained in the Wanfang Database, another large data provider affiliated with the Ministry of Science $\&$ Technology. Moreover, we relied on expert opinion, including by local government officials and Chinese colleagues, who were involved in internal government-sponsored evaluations of university satellite institutes.

Based on these initial inquiries and considerations regarding field access, we chose the Foshan Nanhai Guangdong Technology University CNC Equipment Cooperative Innovation Institute (Foshan GDUT Institute hereafter) as our main case. We subsequently (see Appendix) compare our findings with the two similar cases, which are particularly salient in Chinese policy discourses. One of them is the Research Institute of Tsinghua University in Shenzhen (Shenzhen TU Institute hereafter), which is the very first satellite institute in Guangdong and in China as a whole and is commonly seen as a standard-setting case. The other one is the Guangdong Huazhong University of Science \& Technology Industrial Technology Research Institute (Dongguan HUST Institute hereafter), which is commonly regarded as Guangdong's first successful university satellite institute outside of Shenzhen. Table 1 provides a description of the three cases.

The Foshan GDUT Institute was established in early 2013 in Foshan, a prefecturelevel city situated on the west bank of the Pearl River, neighboring Guangzhou, where the parent university, Guangdong University of Technology (GDUT), Guangdong's largest engineering university, is located. Inhabited by around $7.9 \mathrm{~m}$ residents (in 2018), Foshan has grown into a sizeable manufacturing hub that comprises clusters of nonstate small and medium-sized firms, predominately targeting the domestic market, in sectors such as household appliances and consumer electronics in addition to traditional sectors such as ceramics, metals, and furniture.

The Dongguan HUST Institute was established in 2007, by Huazhong University of Science \& Technology, a national-level university, which leads the country in mechanical science and engineering, from Hubei province's capital Wuhan, which is almost $900 \mathrm{~km}$ away from the satellite institute's host region Dongguan. Bordering Guangzhou to the northwest and Shenzhen to the south, Dongguan with its $8.4 \mathrm{~m}$ inhabitants (in 2018) has originated an industry that is less domestically oriented than Foshan's, and instead is one of China's major export hubs. In addition to furniture, textiles, and toys, Dongguan is particularly known for its $3 \mathrm{C}$ manufacturing industry (computers, communication, and consumer electronics). One of five smartphones sold globally is assembled in Dongguan. Nonetheless, as in Foshan, the industry's high labor intensity and the regional scarcity of innovative capabilities have been a source of concern for policymakers. 


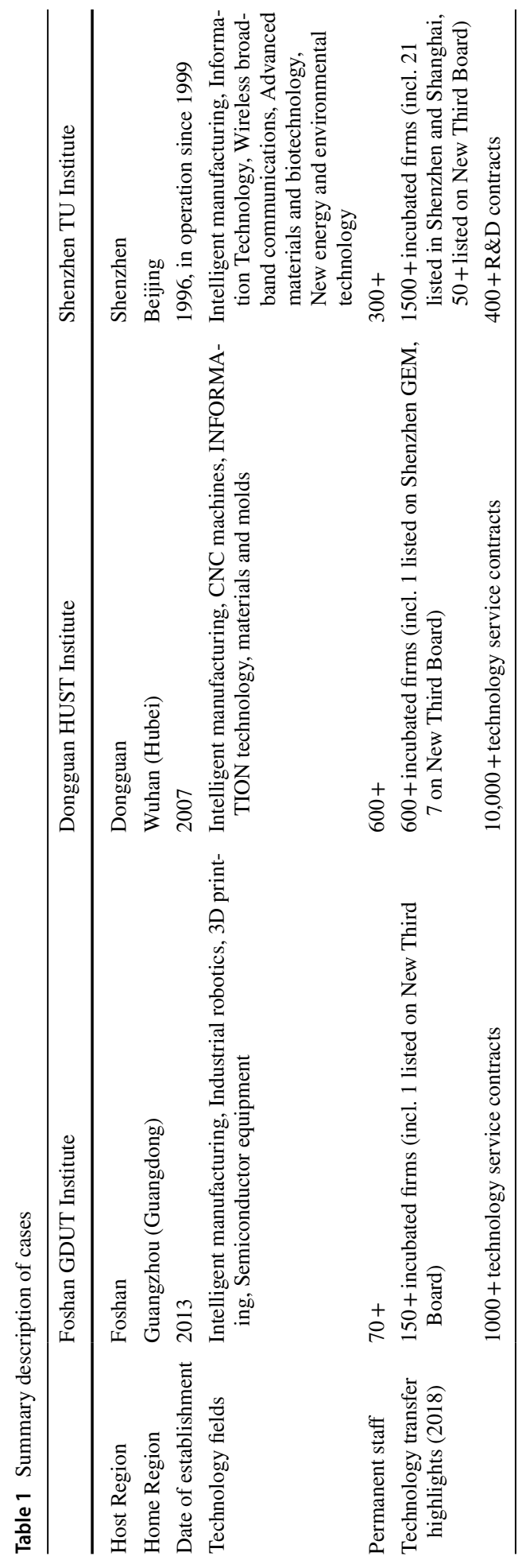


The Shenzhen TU Institute went into operation in 1999 already. It was established by China's most prestigious engineering university, Tsinghua University, in Beijing, almost $2000 \mathrm{~km}$ away from the host region Shenzhen, a prefecture-level city with sub-provincial status, which borders Hong Kong to the south and Dongguan to the northeast. The city is widely known as the location of China's most important special economic zone. Shenzhen has developed into a metropolis of $13 \mathrm{~m}$ inhabitants and one of China's most innovative cities, rivalling Beijing. As China's first university satellite institute, the Shenzhen TU Institute has witnessed the transformation of the city's Nanshan District from a rural agricultural area to Shenzhen's high technology zone with a whole cluster of newly established universities, university satellite campuses and institutes.

\subsection{Data collection}

We collected comprehensive data on the three institutes (see Table 2). Most data was collected during four research stays in Guangdong province during 2018 and 2019, amounting to four months of fieldwork. We cooperated closely with colleagues in Guangzhou, who helped us get in contact with interviewees and interpret our findings. Additionally, we gathered relevant information from the institutes' webpages and from related webpages, including those of the parent universities. Concerning our two replication cases, the Dongguan HUST Institute and the Shenzhen TU Institute, we primarily relied on our own interviews but triangulated our visits to the satellite institutes with existing analyses and institute presentations in Chinese-language innovation and management journals.

Data collection proceeded sequentially. We first focused on our main case-the Foshan GDUT Institute. Our visits to the other two institutes happened at a later stage of data collection, when we had developed a good understanding of the Foshan GDUT Institute case. Thus, our enquiry could be conducted based on a proven structure with harmonized key lines of enquiry, while maintaining sufficient openness for each case's idiosyncratic particularities. In all three cases, we conducted semi-structured interviews with institute representatives in which we asked about the institute's organizational structure, the nature of their technology transfer activities, the activities of complementary ecosystem actors, and interactions with triple helix actors from university, government, and industry. These interviews lasted for at least one hour each and were supplemented by extensive guided tours through the institutes and their exhibition halls.

In the case of the Foshan GDUT Institute, we made two visits at two different points of time and with different interview partners. During our two visits, we built on the written (open-ended) replies of our questionnaire on the institute's activities and relations that we had received beforehand. Additionally, we seized opportunities to access further interview partners that could help us enhance our understanding of the relevant topics and identify issues in need of further clarification, including members of the local government administration and GDUT, and managers of two further GDUT. ${ }^{5}$ We mainly used these further interviews, and our contacts to Chinese colleagues from various universities in Guangzhou, for the purpose of crosschecking and triangulation.

\footnotetext{
5 We did not treat these institutes as separate cases but rather as means to developing more detailed and indepth understandings of our main case. Mukhija (2010) calls this approach „n of one plus some”, arguing that a focus on one case study aided by the pursuit of some additional secondary cases is a fruitful way of conducting in-depth single-case analysis.
} 
Table 2 Overview of data sources

Main case: Foshan GDUT Institute

Interviews relating to the satellite institute

Interviews relating to the local government

Interviews relating to the parent university

Picture material from the satellite institute

Further informational material

Cases for replication

Dongguan HUST Institute

Shenzhen TU Institute
2 Visits involving more than three hours of meetingroom interviews with altogether 3 institute representatives and 1 high-tech zone official (total recorded time: 02:50:39) and guided tours through the institute's exhibition hall together with further institute staff

3 Formal and informal meetings with district government officials

1 Meeting with GDUT professor familiar with university satellite institutes; complementary visits, meetingroom interviews, and exhibition hall tours with 2 further GDUT satellite institute managers at other locations in Guangdong

Informational material from the satellite institute 1 Pre-visit questionnaire; 1 institute ppt; information from institute's own website and from its crowdsourcing platform website (including expert database); information from parent university website

77 Exhibition hall captures providing information on the institute's innovation teams, incubated firms, and service platforms

Written material provided/compiled courtesy of district government on relevant regional innovation policy; Nanhai yearbooks and five-year plans; 4 journal articles on the satellite institute

1 Visit involving a meeting-room interview (total recorded time: 01:19:04) and informal conversations with institute R\&D staff; information from the institute's website; 9 journal articles on the institute

1 Visit involving a meeting-room interview (total recorded time: 01:19:14) and guided tour through the institute's exhibition hall; information from the institute's website; 14 journal articles on the institute; visits to one of the institute's subsidiary S\&T parks

Besides interviews, we gathered written and visual information from various sources for in-depth document analyses, including a detailed presentation on the Foshan GDUT institute that illustrates the institute's major activities, cooperative projects, government relations, and achievements. We especially made use of the information on the institute's webpages and the detailed information presented in the institutes' exhibition halls on the institute's history, services and products, major achievements, and outstanding research staff. Exhibition hall and website captures have proved a prime source of information concerning the geographical and organizational origin of the institute's individual spinoff team members, the spinoff teams' composition, and the spinoffs' relation to the institute's service platforms.

\subsection{Data analysis}

Our data analysis also proceeded in stages. In the initial stage, we first coded our interviews and documents manually following established coding procedures (Gioia et al., 
2013; Villani et al., 2017). We specifically coded our data how the satellite institute representatives described the motivations, rationales, and intentions underlying the institute's activities, how they considered the institute's activities to be connected, and how actors from outside the institutes were involved in the institute's development and operation.

Second, we augmented our exploration of institute activities with a separate analysis of the data on innovation projects and spinoffs that we gained from the Foshan GDUT Institute's exhibition hall and website captures. In that case, the exhibition hall's presentations and poster displays named individual team leaders and important team members related to more than 30 satellite institute spinoffs. We extracted the names of 97 individual entrepreneurial team members and tracked their organizational (usually academic) background by searching the institute's expert database and other reliable websites (e.g. homepages of various universities). The Foshan GDUT Institute exhibition hall presentations also showed how the institute's entrepreneurial teams and spinoffs were connected to other organizational actors to engage in a joint provision of technology services via the institute's service platforms. Based on the relational data, we generated graphs that linked various organizational units of the institute and external parties. On the one hand, these links include those between the satellite institute's spinoffs and the spinoff team members' original universities and firms. On the other hand, they include the cooperative links between the spinoffs and technology firms associated with the institute's service platforms. These graphs helped provide us a good understanding of the structure of the institute's ecosystem and gain an appreciation of the relevant range of actors involved.

Subsequently, we synthesized our data consecutively into thick descriptions of individual case histories, starting with the Foshan GDUT Institute. Each case traces the institute's development trajectory and captures its organization-building accomplishments, the range of activities and intermediary functions performed by the institute, and its interactions with the external environment. We inductively developed a technology transfer model for the Foshan GDUT Institute case that conceptualizes generic activities, interactive spaces, groups of actors, and their interactions. Following a replication logic (Eisenhardt \& Graebner, 2007), we compared and contrasted this model with the data on the other two cases, recognizing similar role structures and interactions among pivotal groups of actors.

In the second stage, we inductively analyzed the interactive ties between the institute and the identified actor groups based on our understanding of the technology transfer models. Iterating between our data and the literature, we organized our initial codes around theory-centered themes, capturing common proximity patterns across our cases.

\section{Findings}

In the following two sections, we present our findings of our main case, the Foshan GDUT Institute. We provide the comparative summary of our two replication cases, the Dongguan HUST Institute and the Shenzhen TU Institute, in the Appendix.

\subsection{The structure of the Foshan GDUT Institute's ecosystem}

The Foshan GDUT Institute, a state-university collaboration that is listed as a major technological innovation project under Foshan's "Plan for Constructing an Innovative City (2013-2020)", was established to advance regional knowledge-based development by engaging in four activities. They include performing innovation services, carrying 
out business incubation, undertaking R\&D on advanced manufacturing technologies and equipment, and enlarging the local science and technology workforce. Cooperating with firms from the region to support their innovation and upgrading efforts has been a particularly important aspect of the institute's mission. However, this was easier said than done: "To tell you the truth, when we came to Foshan, we did not know what the demand was, which direction to take, what would be successful" (Foshan GDUT 02, Q32, Seq. 87). Concerning R\&D, they first thought about developing robots themselves (Foshan GDUT 02, Q18, Seq. 51), but had to recognize that they would be unable to perform $\mathrm{R} \& \mathrm{D}$ on such a large scale "because, on the one hand, capacity is limited and, on the other hand, the demand of firms is very diverse" (Foshan GDUT 02, Q0, Seq. 2). Therefore, the satellite institute has concentrated on technology brokering, which has become the core activity, connecting the institute's other relevant activities from R\&D to business incubation.

Table 3 provides representative quotations regarding the Foshan GDUT Institute's activities. Instead of developing equipment, the institute's management refocused R\&D activities towards identifying and articulating regional demand conditions, developing systems integration solutions, and identifying suitable technology (component) providers. First, this includes performing industry surveys and on-site technology audits as well as conducting industry symposia to determine technological needs. Second, it includes translating these needs into design specifications and constraints to be presented to potential technology suppliers. While the institute had initially ceded the development of custommade solutions to external technology suppliers, problems of information distortion as well as strategic reasons led the institute's R\&D centers to become more heavily involved in specifying technological solutions. Targeting manufacturing automation, for instance, "[w] hat [the institute] actually do[es] is to find out which method-which kind of robot, for instance-could solve the problem. Then, [the institute] provide[s] a systemic solution" (Foshan GDUT 02, Q24, Seq. 68). Examples of such systemic solutions include designing specific robotic workstations and automated assembly systems.

Following demand identification, the Foshan GDUT Institute conducts search activities including technology mining and supplier identification. Its online crowdsourcing platform complements offline matchmaking. Based on this, the institute has established specialized service platforms bringing together various knowledge actors that can supply a technological solution to satisfy regional industrial demand. Service platforms in the robotics field, for instance, provide specialized solutions for automated paint spraying, welding, and polishing, primarily for traditional local manufacturing industries, including sanitary ware, furniture, and metals.

Although the Foshan GDUT Institute is a public institution, it operates like a business. To do so, the non-profit institute has established a for-profit development company that primarily acts as the institute's investment arm, taking stakes in promising spinoff and startup companies. The institute's provision of technology service and business incubation service platforms are public activities that do not generate much income (Foshan GDUT 02, Q40, Seq. 112). However, the platforms provide a foundation for exploiting the institute's positional advantage as a technology broker. The service platforms generate feedback on the size of the regional market that the institute can share with its spinoffs. Accordingly, the institute breeds its own technology suppliers, adding to the service platform's supply side, which originally consists mainly of non-local technology firms. "[I]f the problem turns out to be a problem that a large number of firms have, then this could lead us to establish a firm that scales up the solution" (Foshan GDUT 02, Q21, Seq. 60). By giving those spinoffs access to the service platforms, the institute effectively provides them with a ready market. 
Table 3 Main activities of the Foshan GDUT Institute

\begin{tabular}{|c|c|}
\hline Activity & Representative quotations \\
\hline \multirow[t]{2}{*}{$\begin{array}{l}\text { Local demand } \\
\text { identifica- } \\
\text { tion and } \\
\text { articulation }\end{array}$} & $\begin{array}{l}\text { "Since our establishment in 2013, we have done quite a lot of investigations and surveys on } \\
\text { Foshan's industry, we visit a lot of firms every year. Starting this year, we have changed } \\
\text { our previous strategy, which was to go to individual firms, sound out their demand, and } \\
\text { return to analyze what we could do. This year we tend to participate in the surveys in a } \\
\text { more organized fashion in that we determine several themes beforehand at the begin- } \\
\text { ning of the year. For instance, if we said we were doing this kind of plastics machinery } \\
\text { industry, then we would organize informal industry discussions so that they can bring up } \\
\text { some specific technical needs." (Foshan GDUT 02, Q5, Seq. 21) }\end{array}$ \\
\hline & $\begin{array}{l}\text { "We play the role of a technology broker. We can tease out the firm's demand. Because } \\
\text { when some firms articulate their demand, they actually do it inaccurately. We can } \\
\text { express it very clearly. When there is a demand, then we can solve the problem. That is } \\
\text { to say, what we do concerns technical diagnosis and the provision of technical solutions." } \\
\text { (Foshan GDUT } 02, \text { Q0, Seq. 4) }\end{array}$ \\
\hline \multirow[t]{2}{*}{ Matchmaking } & $\begin{array}{l}\text { "For example, the firm's needs cannot be submitted to the supplier's side directly. When } \\
\text { the needs are transferred from your side, there will be information distortion etc. or there } \\
\text { will problems with customer responsiveness. That's why we stopped doing that last year. } \\
\text { Instead, we do our best to come up with technological solutions. If we come up with } \\
\text { such a solution, then we will have fulfilled our role as a technology broker." (Foshan } \\
\text { GDUT 02, Q23, Seq. 66) }\end{array}$ \\
\hline & $\begin{array}{l}\text { "We always go back and forth between the users [of our platforms]. Like we would often } \\
\text { have industry exchanges or say some exhibitions. For us, it is even more important to } \\
\text { go to exhibitions. For us, it is more important to see which enterprises can meet which } \\
\text { kinds of demand. [...]. Because for this we have a designated department, our innova- } \\
\text { tion and entrepreneurship department. [This department] has a full-time staff whose task } \\
\text { is to bring back potential technology suppliers. In fact, he performs his task online and } \\
\text { offline." (Foshan GDUT 02, Q21, Seq. 58) }\end{array}$ \\
\hline \multirow[t]{2}{*}{ Incubation } & $\begin{array}{l}\text { "Two kinds of products derive from our R\&D. One kind is public. We lean towards doing } \\
\text { more public projects in the future. But if on the basis of our public projects, we can } \\
\text { generate competitive products, then we will try to realize them." (Foshan GDUT 02, Q5, } \\
\text { Seq. 20) }\end{array}$ \\
\hline & $\begin{array}{l}\text { "We can probably just solve } 10 \text { percent of the technological demand. Then, how can we } \\
\text { solve the remaining demand? We incubate firms along the technology chain." (Foshan } \\
\text { GDUT } 02 \text {, Q20, Seq. 56) }\end{array}$ \\
\hline \multirow{2}{*}{$\begin{array}{l}\text { Attraction of } \\
\text { extraregional } \\
\text { knowledge } \\
\text { actors }\end{array}$} & $\begin{array}{l}\text { "These [brought-in experts] are all doing R\&D projects [in our institute]." (Foshan GDUT } \\
\text { 02, Q10, Seq. 31) }\end{array}$ \\
\hline & $\begin{array}{l}\text { "We established an office in Silicon Valley in the United States in November last year. Our } \\
\text { platform wants to attract more domestic and foreign high-end talent and have their teams } \\
\text { enter [our incubator], commercializing their technological achievements, implementing } \\
\text { some of their ideas into products, implement solutions and serve our regional industry." } \\
\text { (Foshan GDUT 01, Q2, Seq. 10) }\end{array}$ \\
\hline
\end{tabular}

As its own R\&D staff is too limited to start as many ventures, the institute teams up with knowledge actors, especially from outside the region, to engage in entrepreneurship. Two groups of incubated firms are particularly relevant. The first group of spinoffs comprises teams led by university researchers. GDUT professors are an important subgroup, but the satellite institute has also attracted researchers from other universities. These researchers are attracted by the prospect of being attached to a university institute, while being supported in their entrepreneurial endeavors. The second group consists of joint ventures with technology firms that the institute has convinced of the regional market size. "[O]ne advantage of our public service platforms is that they can help you to understand the needs of 


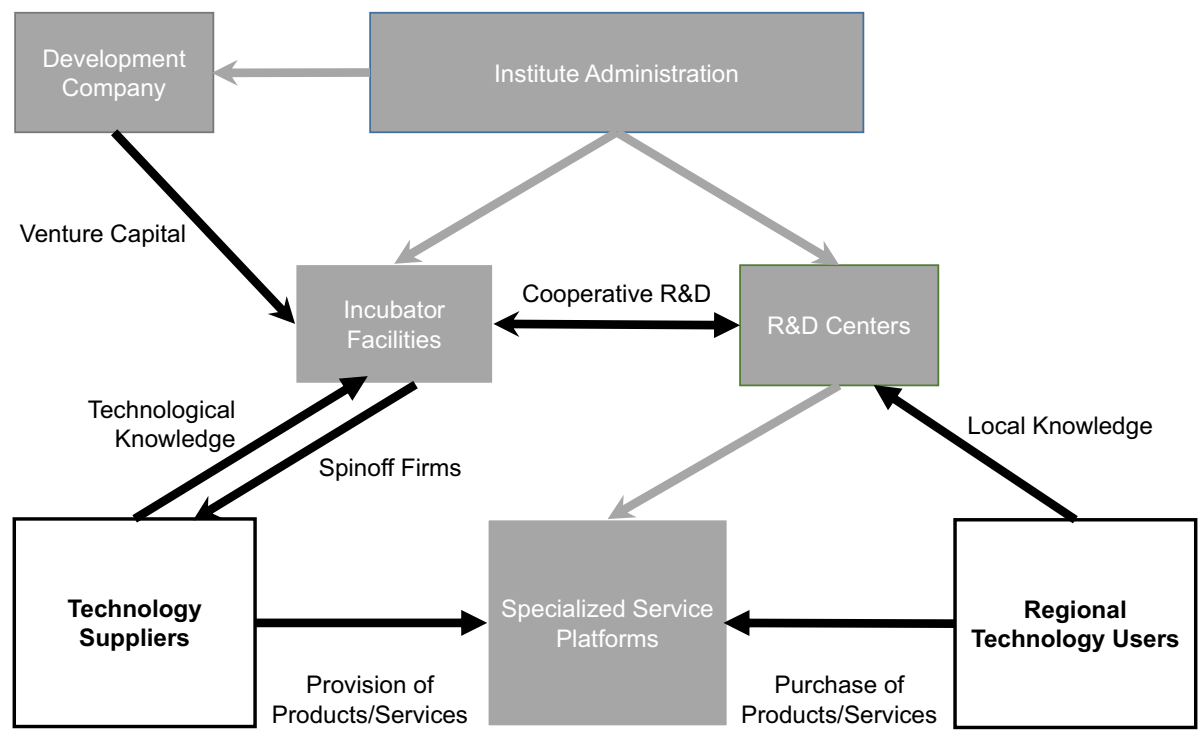

Fig. 2 Foshan GDUT Institute technology transfer structure. Note: Institute-related departments, operational units, firms, and relations in grey

regional industry. [...]. [I]f market demand turns out to be relatively large, then the leading enterprise will naturally want to come here to engage in the incubation of technology” (Foshan GDUT 02, Q21, Seq. 61). Notably, as many spinoffs are related to non-local knowledge actors, the institutes' incubation activities promote localizing the market's supply side.

Figure 2 summarizes the relevant elements of the Foshan GDUT Institute's technology transfer model. The specialized service platforms, which operate as a kind of technology marketplace, constitute the centerpiece of that model. They are established by the institute's R\&D centers based on local (sticky) knowledge concerning specific industry conditions, derived from occasional interactions with regional technology-using firms. The R\&D centers help firms communicate their technological demand via the institute's offline and online platforms to technology suppliers, which are mainly located outside the region. If the institute discovers technological solutions that can be marketed at scale, it invites relevant knowledge actors, from both firms and universities, to establish a spinoff together with the institute to commercialize the technological application. The institute's R\&D collaborations are mainly internalized in the sense that they take place between the institute's R\&D staff and the entrepreneurial teams within the institute's incubator facilities. The content of the collaboration primarily involves the adaptation and application of the relevant actors' technological knowledge to market demand. 


\subsection{Proximities in the Foshan GDUT Institute's ecosystem development}

\subsubsection{Regional industry}

Establishing a satellite institute reduces the geographical distance between parent university and the host region's industry. The reduction is instrumental because information on the regional firms' demand for solutions to their production difficulties does not travel well. In a manufacturing region such as Foshan, there exists a potentially large demand for particular manufacturing-related services and for manufacturing equipment adapted to existing conditions like the firms' technical skills or production space constraints. As mentioned above, the firms have difficulty to transmit this information, while external technology suppliers frequently lack the imagination to recognize the market potential. Locating in the region enables the satellite institute to facilitate user-producer interaction that would not have occurred otherwise. Technology transfer mainly involves the localization (luo di, "to land") of the technology developed at the parent university—or by other non-local knowledge actors. This does not mean that the technology will remain local. Once it is developed, it can be marketed in other regions with similar demand structures. The Foshan GDUT Institute and its spinoffs have already expanded within Guangdong.

GDUT's capacity of accessing relevant information on regional demand conditions is associated with the increase of geographical proximity. To some extent, this change of proximity has facilitated organized proximity to regional industry. The university satellite institute has (co-)established, or joined, regional industry associations and alliances. However, according to our interviews, these organizational ties are not very strong and mainly seem to concern the marketing of the institute's services and the obtainment of government resources. This is mainly due to the regional firms' limited capabilities. ${ }^{6}$ Relatively few firms have the technological capabilities to enter into intensive cooperation with the institute - and, at least until recently, the latter firms' cooperation with the institute is similar to that with non-local knowledge actors (see Sect. 4.2.4). Nonetheless, organized proximity is indirectly relevant for knowledge flows to and from regional industry, as proximities to other ecosystem actors had to be organized to provide the resources and incentives for the Foshan GDUT Institute to engage with regional industry. Especially organized proximity to local government, facilitated by geographical proximity, has been relevant for the development of regional university-industry interaction.

\subsubsection{Local government}

GDUT's locating in the region is directly — and automatically_associated with an increase in organized proximity to the local government. Two forms of organized proximity are relevant in this regard (Table 4). First, while geographical proximity between university and local government is not sufficient to create organized proximity, organized proximity to

\footnotetext{
${ }^{6}$ In our conversations with local government cadres, we have frequently encountered a sense of frustration with local small and medium-sized firms from traditional industries, which have made little progress in R\&D capability development, despite comprehensive policy support for the establishment of corporate R\&D centers. Consequently, local government primarily pins its hope on manufacturing efficiency improvements through automation and the upgrading of equipment, on the one hand, and startup formation and the localization of technology firms, on the other hand. The Foshan GDUT Institute seeks to combine these two directions.
} 
Table 4 Organized proximity to government and associated resource flows

Form Representative quotations

Organized forms of proximity to government

Administrative subordination "[Government financial support came mainly from] the Nanhai district government and from the Management Committee of the High-tech Zone because we belong under the management of the local administration." (Foshan GDUT 01, Q2, Seq. 5)

"The government wants us to build this platform well so that, in the future, it can operate in accordance with their vision. We also have some assessment indicators to fulfill their requirements. They are mainly centered on the Foshan region's needs for industrial restructuring, upgrading, and development." (Foshan GDUT 01, Q2, Seq. 7)

Joint institute governance "Because the whole management, it is based on the institute dean responsibility system under the leadership of the board of directors. [...]. [On the board of directors], the government has more than a few seats." (Foshan GDUT 01, Q22, Seq. 59)

"When we first came to Foshan, we weren't sure where to find the demand, which direction to go, and what would be a good way to do it. [...]. When we had a specifc idea, we [therefore] would report back to the high-tech zone administration or the science and technology bureau, for instance." (Foshan GDUT 02, Q32, Seq. 87)

Associated resource flows

Government funding

Access to regional firms

Project funding and subsidies

Investment promotion

Startup finance
"The construction of this [institute] has received strong support from the government. The government invested 120 million Yuan in the first three years to support the development of the [institute] and support our hardware construction." (Foshan GDUT 01, Q2, Seq. 5)

"Our government sometimes goes to specific companies to investigate, and it will arrange specialized personnel to come with us to grasp the firms' demand." (Foshan GDUT 02, Q21, Seq. 59)

"Last year, we cooperated with the government to develop nine demonstration lines [e.g. for paint spraying]. [...] The government proactively funds this, we do the demonstration lines, and the other firms will accordingly do it [i.e. transform their processes]. This way will accelerated the pace of transformation and upgrading. [...] If a company is interested in a certain demonstration line, it will enjoy the government's preferential policies. Enterprises only pay a small portion of their own money." (Foshan GDUT 01, Q2, Seq. 11-Q3, Seq. 13)

"The government has investment promotion. They will introduce some good [innovation] projects [...]." (Foshan GDUT 01, Q6, Seq. 22)

"We have an angel investment. The government also has some funds that it operates together with us." (Foshan GDUT 01, Q6, Seq. 22)

the government is necessary, though impossible to have without geographical proximity, to enjoy access to local government resources, which facilitate the exploitation of regional market opportunities. GDUT is a provincial-level university but the satellite institute is established as a public institution subordinated to the lower-level "administrative region" (Cooke et al., 1997), responding to the local government's development vision. Second, the satellite institute is established as a joint venture between government and GDUT. Both parties sit on the institute's board of directors and supervise its operation. While the government mainly focuses on providing "guidance", keeping an eye on the institute's contribution to regional industry development, the "institute dean responsibility system" (Foshan 
GDUT 01, Q22, Seq. 59) allows acting deans not only free hand to develop the technology transfer ecosystem but to run the institute as a business venture.

Organized proximity with the local government, not geographical proximity per se, is relevant for the university satellite institute because, in the Chinese setting, the institutional affiliation is critical for attaining local government resources. These resources go beyond the government's initial investment for land, a scarce resource in China, as well as facilities and equipment (Table 4). The local government, which maintains strong ties to regional industry, has been very proactive in bringing the institute in contact with relevant firms by supporting industry surveys, symposia and other means of exchange. It was also the main counterpart to talk about transfer strategies. "Whenever we wanted to do something, had a specific idea, we would report to the high-tech zone administration and the science \& technology bureau. In this way, [our strategy] developed from a relatively vague concept" (Foshan GDUT 02, Q32, Seq. 87). While the local government has shied away from giving out a permanent funding commitment, it keeps on launching numerous policy programs, which the satellite institute, as a subordinated institution, can draw on, with the effect of channeling the institute's activities. In addition to funding applied R\&D and industrial upgrading projects through its own programs, the local government also plays a role in accessing the more substantial project support of higher-level governments at city and provincial level. The same applies to funding for attracting non-local innovation teams, where relevant funds exist from the district (the Nanhai "Blue Ocean Talent Plan") to the city and provincial levels (Foshan/Guangdong innovation team plans). ${ }^{7}$ Due to the organizational ties, the local government guides prospective teams to locate within the satellite institute. Moreover, organized proximity gives the Foshan GDUT Institute the opportunity to access government investment funds for promoting its incubation function.

\subsubsection{Parent university}

Locating the satellite institute within close geographical proximity to actors in the host region produces distance to the parent university-both spatially and organizationally. To ensure the flow of resources from GDUT to its university satellite institute, the geographical divide needed to be bridged. This was achieved by creating organized proximity through a cross-location integration of research functions (Table 5). The Foshan GDUT Institute is organizationally connected to the parent university's relevant engineering departments, the School of Electromechanical Engineering in particular. The connection is both structurally and personally. In terms of structures, the satellite institute links to GDUT's R\&D facilities, while it has established new (government-sponsored) facilities in Foshan. According to the institute's declaration (institute report), "[t]he cooperation between the institute and GDUT is very close, jointly pursuing technology development and platform establishment." Cooperative platform construction includes the establishment of provincial-level engineering centers and, more recently, a manufacturing innovation center for the development of advanced LED packaging technology, responding to local government initiatives to upgrade Foshan's semiconductor industry development. In terms of persons, the Foshan GDUT Institute's dean, recruited by the parent university through its own "Hundred Talents" recruitment program, concomitantly serves as a professor of

\footnotetext{
7 Until mid-2018, the Foshan GDUT Institute had recruited 1 Guangdong Technological Innovation Team, 11 Foshan Innovation Teams, and 1 Nanhai Innovation Team (Institute ppt).
} 
Table 5 Organized proximity to parent university and associated resource flows

Form Representative quotations

Organized form of proximity to the parent university

Cross-location integration of R\&D facilities

"The institute and GDUT jointly established the
'Innovation Center for Semiconductor Intelligent
Equipment and Systems Integration of Guang-
dong Province' and the 'Industrial Technology
Innovation Alliance for Industrial Robotics
Integration and Application of Guangdong Prov-
ince'." (Foshan GDUT Institute Report)
"Because we essentially are Guangdong University
of Technology, and we depend on Guangdong
University of Technology for our operation and
establishment, we also rely on the university for
many research achievements, including micro/
nano manufacturing technology, visual inspection
equipment [...]." (Foshan GDUT 02, Q0, Seq. 9)
"Professors have a chance to get in touch with
entrepreneurship [here in Foshan]. They are only
doing the industrialization here." (Foshan GDUT
02, Q11, Seq. 34)

Associated resource flows

Reputation and R\&D staff

"[GDUT's utility for the institute is] 1) the use of the university's brand, 2) the professors and the talents that are brought in." (Foshan GDUT 01, Q9, Seq. 28)

GDUT's School of Electromechanical Engineering and a top manager within the university's third mission bureaucracy.

These multiple links facilitate the movement of knowledge and people across the two locations. University research staff temporarily come to Foshan to develop and commercialize the technological achievements that they have generated at the parent university. While they are in Foshan, they remain part of GDUT's research departments and facilities. GDUT's "brand" (Foshan GDUT 01, Q9, Seq. 28) is an important resource for the satellite institute to convince researchers to attach to the satellite institute and engage in regional (usually government-supported) technology transfer and commercialization projects. As the projects are carried through, they provide several further high-level R\&D positions, related to GDUT, as well as training and job opportunities for university students and graduates. The university has developed various joint training programs for graduate and postgraduate students that help alleviate personnel shortages for the satellite institute's R\&D projects and the spinoffs in the institute's incubators.

\subsubsection{Non-local knowledge actors}

Establishing a university satellite institute creates the geographical proximity that might be necessary for facilitating university-industry technology transfer to the host region's engineering-based firms and SMEs with low technological capabilities. It may also extend the university's generative role, centering on spinoff and startup formation, to the host region. However, compared to the situation of parent universities and their intermediaries within 
Table 6 Resources for creating proximity with non-local knowledge actors

Resource source Representative quotations

Organized proximity with local government

"For firms, we also provide a policy-oriented contact to government, because the government gives support to firms, including innovation teams. They can receive several government subsidies." (Foshan GDUT 01, Q5, Seq. 20)

"If someone starts a venture here, because we have some policies, for instance, in this park, for tenant space renovation, the government, including the research institute, is in charge of renovation. After renovation, we give him a certain rent-free period, based on the nature of the research project. Every matter can be negotiated independently. Rent is for free, the renovation fee is waived. Then, we will give him some help concerning business registration, the bringing in of talents [i.e. skilled staff], and financial support. In this way, we naturally attract him." (Foshan GDUT 01, Q14, Seq. 39)

Organized proximity with parent university

"They are all doing R\&D projects. Why are all these Thousand Talents in there? Take equipment, for instance. For the project led by [one GDUT professor], he [i.e. the professor] brought two Thousand Talent professors along with him." (Foshan GDUT 02, Q10, Seq. 31)

"The cooperation between the institute and GDUT is very close, jointly pursuing technology development and platform establishment. Together with [several GDUT professors], the institute carries out research projects with a funding size reaching 20.3 million RMB. [...]. Together with [several other GDUT professors], the institute established ten crowdsourcing platform technology teams." (Foshan GDUT Institute Report)

Proximity with regional industry

"If you lack a market, we know Foshan's industry and the regional market demand very well." (Foshan GDUT 02, Q27, Seq. 76)

the well-endowed home region, the satellite institute faces stronger resource constraints. To make an impact on the host region, the institute cannot simply rely on its own innovation resources, nor can it readily draw on knowledge from the regional environment. Accordingly, interregional mobility of R\&D staff between parent university and satellite institute tends to be an integral part of the development of university satellite institutes. This requires organized proximity. However, even then, the knowledge flows are not sufficient to promote regional knowledge-based development. The Foshan GDUT Institute therefore seeks to accommodate and attract not only knowledge from the parent university but from a larger variety of actors, whose technological proximity to the host region's existing industry might help in promoting regional development goals. To achieve this, despite the locational disadvantages of a non-metropolitan region, the institute primarily focuses on developing an ecosystem that is conducive for anchoring non-local knowledge-with the institute aspiring to become "a big platform for integrating resources" (Foshan GDUT 01, Q36, Seq. 87).

Table 6 provides representative quotations on how institute representatives consider the relevant proximity relations. The picture that emerges from the statements is that the 
satellite institute seeks to create a strong bundle of complementary resources that is sufficiently attractive for non-local actors to come to the region, at least temporarily. The institute derives these resources from the proximities that it has established to the previously mentioned ecosystem actors. Organized proximity to the local government and the parent university are relevant in this regard. Geographical and, to a lesser extent, organized proximity to regional industry enables the institute to access the information that the institute's R\&D centers transform into a (demand) resource to be offered to prospective entrepreneurial actors. In this sense, the Foshan GDUT Institute views itself less as a conventional R\&D Institute than as an ecosystem facilitator that develops the conditions for the commercialization of technology by non-local entrepreneurs and innovation teams.

\section{Discussion: proximity relations and innovation resource flows}

Our three case studies, including the replication cases in the Appendix, indicate how locating university satellite institutes within knowledge-peripheral (host) regions can help overcome local barriers to university-industry interaction, interregional technology transfer, and innovation. They can do so by brokering relevant knowledge to local industry and by gathering resources to create a critical mass for attracting external resources. The two functions are similar to the "deepening" and "widening" roles identified by Benneworth et al. (2009). Concerning their deepening role, our focal institutes keep to the lesson that to stimulate regional industrial development, academic institutions need to adapt to their innovation environment (Bonaccorsi, 2017; Isaksen \& Karlsen, 2010). Accordingly, the satellite institutes focus on applied research and targeting the region's industrial demand for technology. This is in line with other recent research highlighting the role of universities regarding nascent and incremental innovation activities in emerging economies (Storz et al., 2021) and of university applied research as "an effective means to increase innovation output and to foster innovation outside major innovation centers" (Pfister et al., 2021). Concerning their widening role, our focal institutes provide a platform to which knowledge actors can connect. Resembling recent research by Harima et al. (2021), our study highlights the relevance of non-local entrepreneurs for overcoming resource scarcity-one of the pivotal problems in less developed ecosystems (Cao \& Shi, 2020). The focus of our research is yet on the proximity dynamics that allow satellite research institutes to perform the two roles jointly.

For university satellite institutes, geographical proximity is important as both an antecedent and an outcome. The university's local presence facilitates regionally mediated knowledge spillovers pertaining to local industry conditions. Geographical proximity is necessary for university satellite institutes to grasp their potential contribution to regional industry development. Regional industrial firms, in turn, can profit from spillovers by the satellite institutes, though the externalities are mostly pecuniary (Breschi \& Lissoni, 2001), concerning productivity gains from the purchase of products and services. By connecting to regional industry, university satellite institutes gain access to market information, which they can combine with complementary resources from the local government and from their parent university based on emergent organized proximities. By combining these resources, university satellite institutes create conditions that are conducive to attracting relevant knowledge actors from outside the region, who they rely on for performing their activities, ranging from technology services to spinoff formation. Creating an open platform for attracting and anchoring non-local knowledge is the key function that characterizes 


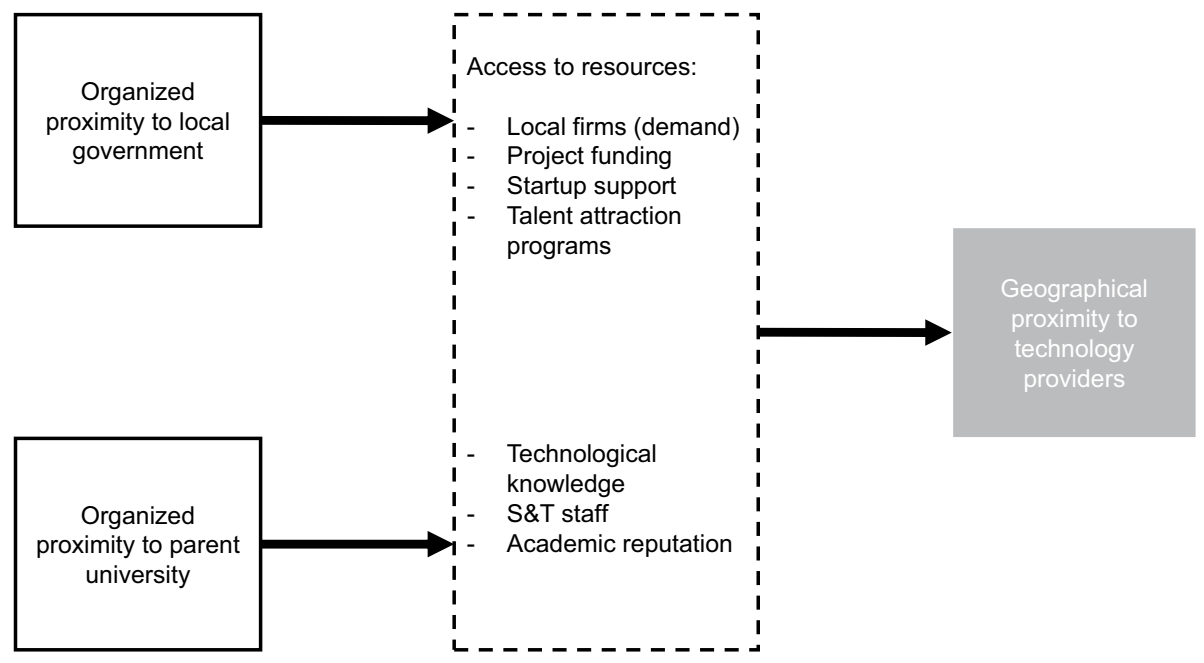

Fig. 3 Relevant proximity relations and innovation resource flows

our three satellite institutes. Ecosystem development supports the attraction of non-local knowledge providers, including individual researchers, technical staff, innovation teams, and technology firms, and their stay at the institute to commercialize knowledge within the region.

As we know from the proximity literature, geographical proximity can facilitate organized proximity (Boschma, 2005) — not only in academic-industry cooperation (Crescenzi et al., 2017) but even more so in academic-governmental cooperation (Ponds et al., 2007), ${ }^{8}$ and in entrepreneurial ecosystems (Brown \& Mason, 2017). Our research on university satellite institutes affirms this facilitation effect but draws particular attention to the reverse proximity relation. Our cases highlight the importance of organized proximity to pivotal ecosystem actors, local government, and (non-local) parent university, for generating geographical proximity to non-local knowledge actors. This includes instances of "temporal geographical proximity" (Torre \& Rallet, 2005), which do not materialize without attractive regional platforms to connect to. While non-local knowledge is important for knowledge-based regional development, it is difficult to harness in regions lacking endogenous knowledge dynamics due to the regions' limited availability of local knowledge, low degree of attractiveness to non-local knowledge actors, and low absorptive capacities for external knowledge (Trippl et al., 2018). Only by fostering the relevant organized proximities, successful university satellite institutes can gather and combine the requisite innovation resources to overcome these barriers and promote the anchoring of mobile knowledge within the region (Crevoisier \& Jeannerat, 2009).

\footnotetext{
${ }^{8}$ Previous research has shown that Chinese domestic universities and firms are more likely to interact when they belong either to the same vertical administration or to the same horizontal (regional) administration (Hong and $\mathrm{Su}$ 2013). If colocated universities and firms are subordinated under different vertical administrations, they may actually not cooperate, despite geographical proximity, turning to spatially more distant, yet institutionally colocated actors instead. The establishment of a university satellite institute solves this problem as it creates an overlap between geographical and organized proximity.
} 
Figure 3 features the pivotal proximity relations. We propose that these proximity relations are fundamental to the development of functioning technology transfer ecosystems by university satellite institutes in general. The Chinese setting is specific in terms of the governance aspects of the relevant ecosystem (Audretsch et al., 2019; Cunningham et al., 2019) - the forms of organized proximity to the mentioned ecosystem actors and the quantity and quality of innovation resource flows involved. Government support is an essential element in maintaining the satellite institutes' technology transfer activities. In many regional contexts, governments do not sustain their support over longer periods (Yigitcanlar et al., 2017). Although public support of Guangdong's university satellite institutes is not permanent, organized proximity keeps regional governments committed to the institutes' development, entailing substantial resource flows that range from R\&D project funding, subsidies for regional firms' purchase of the institute's products and services, talent attraction programs, and startup finance. On the other hand, organized proximity to the parent university, which, in the Chinese setting, is led by government to promote interregional knowledge transfer, provides satellite institutes with access to the university's reputation, R\&D facilities, and, to some extent, its talent pool.

\section{Conclusion}

By establishing satellite institutes, universities can extend their third mission activities to regions in the knowledge periphery, which suffer from a weak knowledge infrastructure, a low degree of attractiveness for non-local knowledge actors, and low absorptive capacities for external knowledge. In so doing, universities can contribute to overcoming the region's barriers to endogenous path development. We maintain that the level and intensity of R\&D cooperation with local firms is possibly less important than commonly assumedespecially with technology firms, which are often able to collaborate with partners independent of geographical distance. According to our analysis, the university satellite institute's pivotal contribution is to develop an ecosystem for attracting and accommodating non-local knowledge-not merely from the parent university but more generally, from other non-local sources with related technology profiles to advance regional development goals. Successful university satellite institutes tackle one of the central challenges keeping knowledge-peripheral regions back-the problem of "how exogenous knowledge could be attracted to thin [regional innovation systems]" (Trippl et al., 2018: 698).

The university's local presence, via its satellite institute, is necessary to reach out to the host region's industry, but not sufficient. In Guangdong's manufacturing regions, university satellite institutes, like the ones examined in this paper, create markets for technology firms and provide upgrading services for local SMEs, which are unable to communicate their technological needs across distances. To perform these activities, the institutes primarily rely on non-local knowledge actors, which they attract to the region by supporting those actors' entrepreneurial pursuits. They do so by mobilizing complementary innovation resources for new venture formation, drawing on organized proximities to relevant ecosystem actors, especially the parent university and the local government. As to the emergent technology transfer ecosystems, organized proximities facilitate the geographical proximity of relevant knowledge actors. In the Chinese setting, the regional proliferation of university satellite institutes builds on an understanding of satellite institutes as being facilitators of ecosystem development, capable of gathering and orchestrating resources for promoting permanent and temporal geographical proximity of knowledge actors. Whereas the relevant 
proximity dynamics are at the core of China's regional innovation policy, they have yet to move into the focus of the relevant literature on interregional technology transfer and regional innovation policy in other countries and regions.

This study is not without limitations. First, despite the mentioned differences, our three cases are similarly located in regions that initially were limited in terms of research institutions and attractiveness to academics but had highly developed industrial dynamics. The regions are therefore quite distinct from regional university towns (Yigitcanlar et al., 2017) or thinly populated regions (Melancon \& Doloreux, 2013), which seek to jump-start industry in the first place. As has been pointed out (Eder, 2019; Zukuskaite et al., 2017), the knowledge periphery itself covers a large variety of institutional and organizational thickness. Our research is merely focused on one type of knowledge periphery, although we believe that the technology transfer model is adaptable to other peripheral regions. Second, the analysis concentrates on direct interactions between the university satellite institutes and other ecosystem actors, omitting indirect links. University intermediaries are yet often located in technology parks and high-tech zones, which are established to promote regional clustering processes (Zouain et al., 2007). These parks may accommodate further intermediaries occupying similar positions and performing similar functions to the satellite institutes. In our three study regions, the local governments have established between seven and twelve satellite institutes with distinct universities. These (and further) intermediaries will partly compete for innovation projects and government funding, but more importantly, can help to enhance the region's overall attractiveness for entrepreneurs and knowledge workers-just like the technology parks in which they are located. Third, our study did not cover the government's complementary urbanization and megacity building initiatives in the Pearl River Delta Greater Bay Area, which likely also contribute to increasing the viability of the satellite institutes' strategy of attracting non-local entrepreneurial teams. Current infrastructure investments for increasing the connectivity of Dongguan's high-tech zone with Shenzhen and Guangzhou, for instance, presumably increase the attractiveness of colocation with the Dongguan HUST Institute. Fourth, the results from our exploratory study could be strengthened by quantitative analyses of performance variation within the whole population of Guangdong's university satellite institutes, assuming data availability. Finally, and more generally, comparative analyses are essential to further advance the research on university satellite institutes and their ecosystems. This includes, inter alia, comparisons with university satellite institutes in other Chinese provinces, other countries or other types of peripheral regions as well as between domestic university satellite institutes and international university research ventures (from the United States, for instance, see Kolesnikov et al., 2019), specifically with a focus on the proximity relations explored in this paper.

Further research should zero in on the university satellite institutes' platform charactertheir role in arranging accessible local and non-local resources to obtain regionally scarce innovation resources, particularly entrepreneurial resources, from outside the region and, in this way, promote selected regional techno-industrial development goals. We assume that it would be particularly worthwhile to study the role of specialized satellite institutes and similar platforms from a regional innovation policy perspective, specifically relating to "missionoriented" policy approaches aimed at promoting "transformative" activities within peripheral regions (Foray, 2018). Important topics include the governance and incentive systems involved in the setting of the institutes' priorities, the relevant opportunity structures and resource conditions, the relationship with complementary regional strategies, especially science and technology parks, and the institutes' effectiveness in gaining development-promoting innovation teams and projects from outside the region. 


\section{Appendix: Replication cases}

The Foshan GDUT Institute was initiated relatively recently, during the last of the three periods mentioned in Sect. 3.1., based on experiences with university satellite institutes established during the previous two periods. For each of the former periods, one satellite institute has drawn particular attention within Chinese academic and policy circles, including the Shenzhen TU Institute during the first, and the Dongguan HUST Institute during the second period. While the three institutes differ slightly in their platform strategies, they feature similar proximity relations and resource configurations geared towards accommodating non-local knowledge actors.

The Dongguan HUST Institute, which is a government-university collaboration involving Huazhong University of Science and Technology (HUST) from Wuhan (Hubei province), one of China's most prestigious engineering universities, is particularly close to the technology transfer model explored in the main paper. The satellite institute is organizationally linked to the parent university's School of Mechanical Science and Engineering, which, as a major institution for intelligent manufacturing R\&D, boasts numerous national and regional-level key laboratories and engineering research centers. The acting dean of the Dongguan HUST Institute holds concurrent leading positions at the mentioned School of Mechanical Science and Engineering and its State Engineering Research Center of Digital Manufacturing and Equipment. In these authoritative functions, he has overseen the transfer of technology (e.g. radio-frequency identification technology) and people from the parent university to the satellite institute, in addition to accommodating innovation teams from elsewhere in China and beyond. At the satellite institute, the staff is located at the branch centers of the parent university's R\&D facilities or the centers that were newly established with the support of the local government in Guangdong. In Dongguan, the R\&D staff is focused on developing applications for technology, originated at the parent university or elsewhere, to meet regional demand (Dongguan HUST, Q7, Seq. 23).

To connect to regional industry, the Dongguan HUST Institute has established four service centers, with close links to the institute's four R\&D divisions, which provide services relating to product design, laser processing, product testing, and industrial internet of things technologies. Having the local government as co-initiator and enabler was instrumental in making contacts with regional industrial firms and in promoting the institute's services (Dongguan HUST, Q30, Seq. 75). Contrary to the Foshan case, the Dongguan satellite institute has established organizational proximity to many firms over the past years, in terms of repeated business interactions and collaborative R\&D, mainly centering on product design (Dongguan HUST, Q15-16). As in the case of the Foshan GDUT Institute, business incubation is an important activity. In addition to providing incubation services to the public, the institute has established almost 70 subsidiary firms (as of 2019), which commercialize the institute's services (e.g. brand and product design, industrial park management) and technologies (e.g. industrial identification products, testing equipment for various regional industries). Some of these firms have expanded their reach to other Guangdong regions or have even established subsidiaries in further Chinese provinces. The initial impetus for pursuing this strategy is similar to the Foshan case. "Since the government does not provide core funding, you have to turn to the market to earn revenue for development [...] but from the perspective of viability, if you want to grow larger, this way it will be difficult. Therefore, the long-term mechanism is [...] to establish companies and gradually develop an investment function.” (Dongguan HUST, Q12, Seq. 38). As the Dongguan HUST Institute has developed its reputation, it has increasingly become a pole 
of attraction for graduates from universities in Guangdong and for technical staff performing the institute's standard services.

The Shenzhen TU Institute goes back to a joint initiative by the Shenzhen government and Tsinghua University, China's most renowned engineering university situated in Beijing. As the country's earliest university satellite institute, and as a pivotal constituent of the host city's high-tech zone development, the Shenzhen TU Institute has inspired the establishment of similar institutes throughout the country. Due to its longer history, and the metropolitan environment that it helped create, the institute's presentday technology transfer model differs slightly from the other two satellite institutes in that technology consulting and services play a less prominent role. Instead, the institute has developed a much stronger R\&D function, involving six research centers, each consisting of numerous research labs, a few of them launched together with companies (for contract R\&D). As a local research institution, the local government has played a strong supportive role in R\&D development. As of 2018, the Shenzhen TU Institute boasted two provincial-level and 19 municipal-level laboratories. In addition, it had established branch centers linking the satellite institute organizationally to two of Tsinghua University's (national-level) state key laboratories. Tsinghua University's commitment to the satellite institute was underlined by sending a high-level university cadre - a vice dean, having leading positions in Tsinghua University's Science \& Technology Division and in the Department of Precision Instruments and Mechanical Engineering-to become the Shenzhen TU Institute's inaugural dean (Shenzhen TU, Q4, Seq. 8). The dean's high-level status helped develop and strengthen organizational relationships to both state entities involved, the parent university (a vice-ministerial-level institution) and local government, and overcome liability-of-newness issues concerning the institute's novel technology transfer model.

During the last two decades, the Shenzhen TU Institute has developed its transfer model based on two advantages deriving from organizational proximity to government-access to land, as a source of rental income, and to the state-controlled financial system, which allowed the institute to launch one of China's earliest venture capital firms. In conjunction with the parent university's resources, especially its reputation, the satellite institute has become an attractive platform for non-local knowledge actors. The institute's R\&D centers are typically headed by Tsinghua university professors and staffed with post-doc researchers, with the institute claiming to have established the largest post-doc workstation in Shenzhen. Apart from the parent university's staff and students, the institute also appeals to top talent from further domestic institutions as well as returned experts and students. Its integrated approach to applied $\mathrm{R} \& \mathrm{D}$ and startup formation plays a decisive role. "Now why is [the researcher] willing to come to us? He comes because he can become our [institute] employee and start a firm at the same time. We allow him to establish a firm, and we can give him as much as 70 percent of the equity in the firm. That is, you do not have to spend any of your money to start a firm and can secure 70 percent of the equity" (Shenzhen TU, Q15, Seq. 36). As the satellite institute's distinct characteristic, virtually all of the institute's laboratories and engineering centers have established their own firms to commercialize the research achievements, hire staff, and distribute the returns (Shenzhen TU, Q15). The satellite institute, which itself has established a listed corporation, Leaguer Group, focuses on strategic alignment, property management, and financial services. In terms of strategy, it strictly orientates its R\&D towards regional demand. "We establish [a lab] only when there is demand. If no one will pay, neither government nor a company, then we will not establish [it]" (Shenzhen TU, Q34, Seq. 101). The institute's financial arm, by now a 
diversified financial service company, provides comprehensive capital support to promote the exploitation of technological knowledge through spinoff formation.

Acknowledgements The authors wish to thank their colleagues Haixiong Qiu, Qing Qiu, Karl Wu, and Yutu Yang from the Institute for Reform and Development of Pearl River Delta at Sun Yat-sen University for their cooperation and support during field research. They also gratefully acknowledge the assistance, comments, and suggestions of Egbert Amoncio, Fei Wang, Rainer Frietsch, Ingo Liefner, Sibei Lin, Yixin Liu, Boy Lüthje, Kazuyuki Motohashi, Yanbo Wang, Wei Zhao, and Na Zou. This work was supported by the Deutsche Forschungsgemeinschaft DFG (Grant Numbers: TE 1069/5-1, TE 1069/5-2; STO 860/8-1, STO 860/8-2; further conceptual work on the manuscript: KR 4895/2).

Funding Open Access funding enabled and organized by Projekt DEAL. This work was supported by the Deutsche Forschungsgemeinschaft DFG (Grant Numbers: TE 1069/5-1, TE 1069/5-2; STO 860/8-1, STO 860/8-2; further conceptual work on the manuscript: KR 4895/2).

\section{Declarations}

Conflict of interest The authors have no conflicts of interest to declare that are relevant to the content of this article.

Availability of data and material The datasets generated during and/or analyzed during the current study are not publicly available due to confidentiality concerns but are available from the corresponding author on reasonable request.

Open Access This article is licensed under a Creative Commons Attribution 4.0 International License, which permits use, sharing, adaptation, distribution and reproduction in any medium or format, as long as you give appropriate credit to the original author(s) and the source, provide a link to the Creative Commons licence, and indicate if changes were made. The images or other third party material in this article are included in the article's Creative Commons licence, unless indicated otherwise in a credit line to the material. If material is not included in the article's Creative Commons licence and your intended use is not permitted by statutory regulation or exceeds the permitted use, you will need to obtain permission directly from the copyright holder. To view a copy of this licence, visit http://creativecommons.org/licenses/by/4.0/.

\section{References}

Adams, J. D., Chiang, E. P., \& Starkey, K. (2001). Industry-university cooperative research centers. Journal of Technology Transfer, 26, 73-86.

Allison, J., \& Eversole, R. (2008). A new direction for regional university campuses: catalyzing innovation in place. Innovation: the European Journal of Social Science Research, 21(2), 95-109.

Almeida, A., Figueiredo, A., \& Rui Silva, M. (2011). From concept to policy: Building regional innovation systems in follower regions. European Planning Studies, 19(7), 1331-1356.

Asheim, B. T., \& Coenen, L. (2006). Contextualising regional innovation systems in a globalising learning economy: On knowledge bases and institutional frameworks. Journal of Technology Transfer, 31, $163-173$.

Asheim, B., \& Gertler, M. S. (2005). The geography of innovation: Regional Innovation systems. In J. Fagerberg, D. C. Mowery, \& R. R. Nelson (Eds.), The Oxford handbook of innovation (pp. 291-317). Oxford University Press.

Audretsch, D. B., Cunningham, J. A., Kuratko, D. F., Lehmann, E. E., \& Menter, M. (2019). Entrepreneurial ecosystems: Economic, technological, and societal impacts. Journal of Technology Transfer, 44, 313-325.

Benneworth, P., \& Hospers, G. (2007). The New economic geography of old industrial regions: Universities as global-local pipelines. Environment and Planning c: Politics and Space, 25(6), 779-802.

Benneworth, P., \& Fitjar, R. D. (2019). Contextualizing the role of universities to regional development: Introduction to the special issue. Regional Studies, Regional Science, 6(1), 331-338. 
Benneworth, P., Coenen, L., Moodysson, J., \& Asheim, B. (2009). Exploring the multiple roles of Lund University in strengthening Scania's regional innovation system: Towards institutional learning? European Planning Studies, 17(11), 1645-1664.

Benneworth, P., Pinheiro, R., \& Karlsen, J. (2017). Strategic agency and institutional change: Investigating the role of universities in regional innovation systems (RISs). Regional Studies, 51(2), 235-248.

Bercovitz, J., Feldman, M., Feller, I., \& Burton, R. (2001). Organizational structure as a determinant of academic patent and licensing behavior: An exploratory study of Duke, Johns Hopkins, and Pennsylvania State Universities. Journal of Technology Transfer, 26, 21-35.

Bonaccorsi, A. (2017). Addressing the disenchantment: Universities and regional development in peripheral regions. Journal of Economic Policy Reform, 20(4), 293-320.

Boschma, R. A. (2005). Proximity and innovation: A critical assessment. Regional Studies, 39(1), 61-74.

Bozeman, B. (2000). Technology transfer and public policy: A review of research and theory. Research Policy, 29, 627-655.

Breschi, S., \& Lissoni, F. (2001). Knowledge spillovers and local innovation systems: A critical survey. Industrial and Corporate Change, 10(4), 975-1005.

Brescia, F., Colombo, G., \& Landoni, P. (2016). Organizational structures of knowledge transfer offices: An analysis of the world's top-ranked universities. Journal of Technology Transfer, 41, 132-151.

Brown, R. (2016). Mission impossible? Entrepreneurial universities and peripheral regional innovation systems. Industry and Innovation, 23(2), 189-205.

Brown, R., \& Mason, C. (2017). Looking inside the spiky bits: A critical review and conceptualization of entrepreneurial ecosystems. Small Business Economics, 49, 11-30.

Calcagnini, G., Favaretto, I., Giombini, G., Perugini, F., \& Rombaldoni, R. (2016). The role of universities in the location of innovative start-ups. Journal of Technology Transfer, 41, 670-693.

Cao, Z., \& Shi, X. (2020). A systematic literature review of entrepreneurial ecosystems in advanced and emerging economies. Small Business Economics, 57, 75-110.

Carrincazeaux, C., \& Coris, M. (2011). Proximity and innovation. In P. Cooke, B. Asheim, R. Boschma, R. Martin, D. Schwartz, \& F. Tödtling (Eds.), Handbook of regional innovation and growth (pp. 269281). Edward Elgar.

Carrincazeaux, C., Lung, Y., \& Vicente, J. (2008). The Scientific trajectory of the french school of proximity: Interaction- and institution-based approaches to regional innovation systems. European Planning Studies, 16(5), 617-628.

Charles, D. (2016). The rural university campus and support for rural innovation. Science and Public Policy, 43(6), 763-773.

Chen, A., Patton, D., \& Kenney, M. (2016). University technology transfer in China: A literature review and taxonomy. Journal of Technology Transfer, 41, 891-929.

Conlé, M., Zhao, W., \& ten Brink, T. (2021). Technology transfer models for knowledge-based regional development: New R\&D institutes in Guangdong, China. Science and Public Policy, 48(1), 132-144. https://doi.org/10.1093/scipol/scaa063

Cooke, P., \& Leydesdorff, L. (2006). Regional development in the knowledge-based economy: The construction of advantage. Journal of Technology Transfer, 31, 5-15.

Cooke, P., Uranga, M. G., \& Extebarria, G. (1997). Regional innovation systems: Institutional and organisational dimensions. Research Policy, 26, 475-491.

Crescenzi, R., Filippetti, A., \& Iammarino, S. (2017). Academic inventors: Collaboration and proximity with industry. Journal of Technology Transfer, 42, 730-762.

Crevioisier, O., \& Jeannerat, H. (2009). Territorial knowledge dynamics: From the proximity paradigm to multi-location milieus. European Planning Studies, 17(8), 1223-1241.

Cunningham, J. A., Menter, M., \& Wirsching, K. (2019). Entrepreneurial ecosystem governance: A principal investigator-centered governance framework. Small Business Economics, 52, 545-562.

Davids, M., \& Frenken, K. (2018). Proximity, knowledge base and the innovation process: Towards an integrated framework. Regional Studies, 52(1), 23-34.

De Fuentes, C., \& Dutrénit, G. (2016). Geographic proximity and university-industry interaction: The case of Mexico. Journal of Technology Transfer, 41, 329-348.

Deste, P., Guy, F., \& Iammarino, S. (2013). Shaping the formation of university-industry research collaborations: what type of proximity does really matter? Journal of Economic Geography, 13, 537-558.

Eder, J. (2019). Innovation in the periphery: A critical survey and research agenda. International Regional Science Review, 42(2), 119-146.

Eisenhardt, K. M., \& Graebner, M. E. (2007). Theory building from cases: Opportunities and challenges. Academy of Management Journal, 50(1), 25-32.

Etzkowitz, H., \& Klofsten, M. (2005). The innovating region: Towards a theory of knowledge-based regional development. $R \& D$ Management, 35(3), 243-255. 
Etzkowitz, H., Webster, A., Gebhardt, C., \& Terra, B. R. C. (2000). The future of the university and the university of the future: Evolution of ivory tower to entrepreneurial paradigm. Research Policy, 29, $313-330$.

Feldman, M. P. (1999). The new economics of innovation, spillovers and agglomeration: A review of empirical studies. Economics of Innovation and New Technology, 8, 5-25.

Fitjar, R. D., \& Gjelsvik, M. (2018). Why do firms collaborate with local universities? Regional Studies, 52(11), 1525-1536.

Fitjar, R. D., \& Rodríguez-Pose, A. (2017). nothing is in the air. Growth and Change, 48(1), 22-39.

Foray, D. (2018). Smart specialization strategies as a case of mission-oriented policy-a case study on the emergence of new policy practices. Industrial and Corporate Change, 27(5), 817-832.

Fritsch, M., \& Aamoucke, R. (2013). Regional public research, higher education, and innovative start-ups: An empirical investigation. Small Business Economics, 41, 865-885.

Fuster, E., Padilla-Meléndez, A., Lockett, N., \& del-Águila-Obra. (2019). The emerging role of university spin-off companies in developing regional entrepreneurial university ecosystems: The case of Andalusia. Technological Forecasting and Social Change, 141, 219-231.

Geuna, A., \& Muscio, A. (2009). The governance of university knowledge transfer: A critical review of the literature. Minerva, 47, 93-114.

Gibbons, M., Limoges, C., Nowotny, H., Schwartzman, S., Scott, P., \& Trow, M. (1994). The new production of knowledge: The dynamics of science and research in contemporary societies. Sage.

Gioia, D. A., Corley, K. G., \& Hamilton, A. L. (2013). Seeking qualitative rigor in inductive research: Notes on the Gioia methodology. Organizational Research Methods, 16(1), 15-31.

Good, M., Knockaert, M., \& Soppe, B. (2020). A typology of technology transfer ecosystems: How structure affects interactions at the science-market divide. Journal of Technology Transfer, 45, 1405-1431.

Grillitsch, M., \& Nilsson, M. (2015). Innovation in peripheral regions: Do collaborations compensate for a lack of local knowledge spillovers? Annals of Regional Science, 54, 299-321.

Gunasekara, C. (2006). Reframing the role of universities in the development of regional innovation systems. Journal of Technology Transfer, 31, 101-113.

Hansen, T. (2015). Substitution or overlap? The relations between geographical and non-spatial proximity dimensions in collaborative innovation projects. Regional Studies, 49(10), 1672-1684.

Harima, A., Harima, J., \& Freiling, J. (2021). The injection of resources by transnational entrepreneurs: Towards a model of the early evolution of an entrepreneurial ecosystem. Entrepreneurship and Regional Development, 33(1-2), 80-107.

Harmaakorpi, V., Tura, T., \& Melkas, H. (2011). Regional innovation platforms. In P. Cooke, B. Asheim, R. Boschma, R. Martin, D. Schwartz, \& F. Tödtling (Eds.), Handbook of regional innovation and growth (pp. 556-572). Edward Elgar.

Hayter, C. S., Nelson, A. J., Zayed, S., \& O’Connor, A. C. (2018). Conceptualizing academic entrepreneurship ecosystems: A review, analysis and extension of the literature. Journal of Technology Transfer, 43, 1039-1082.

Heaton, S., Siegel, D. S., \& Teece, D. J. (2019). Universities and innovation ecosystems: A dynamic capabilities perspective. Industrial and Corporate Change, 28(4), 921-939.

Hong, W., \& Su, Y.-S. (2013). The effect of institutional proximity in non-local university-industry collaborations: An analysis based on Chinese patent data. Research Policy, 42, 454-464.

Isaksen, A., \& Karlsen, J. (2010). Different modes of innovation and the challenge of connecting universities and industry: Case studies of two regional industries in Norway. European Planning Studies, 18(12), 1993-2008.

Isaksen, A., \& Trippl, M. (2017). Exogenously led and policy-supported new path development in peripheral regions: Analytical and synthetic routes. Economic Geography, 93(5), 436-457.

Knoben, J., \& Oerlemans, L. A. G. (2006). Proximity and inter-organizational collaboration: A literature review. International Journal of Management Review, 8(2), 71-89.

Kolesnikov, S., Woo, S., Li, Y., Shapira, P., \& Youtie, J. (2019). Mapping the emergence of international university research ventures. Journal of Technology Transfer, 44, 1134-1162.

Koschatzky, K., \& Stahlecker, T. (2010). The emergence of new modes of R\&D services in Germany. Service Industries Journal, 30(5), 685-700.

Lagendijk, A., \& Lorentzen, A. (2007). Proximity, knowledge and innovation in peripheral regions. On the intersection between geographical and organizational proximity. European Planning Studies, 15(4), 457-466.

Lamine, W., Mian, S., Fayolle, A., Wright, M., Klofsten, M., \& Etzkowitz, H. (2018). Technology business incubation mechanisms and sustainable regional development. Journal of Technology Transfer, 43, 1121-1141. 
Laursen, K., Reichstein, S., \& Salter, A. (2011). Exploring the effect of geographical proximity and university quality on university-industry collaboration in the United Kingdom. Regional Studies, 45(4), 507-523.

Lawton Smith, H. (2003). Knowledge organizations and local economic development: The cases of Oxford and Grenoble. Regional Studies, 37(9), 899-909.

Lecluyse, L., Knockaert, M., \& Spithoven, A. (2019). The contribution of science parks: A literature review and future research agenda. Journal of Technology Transfer, 44, 559-595.

Link, A. N., Siegel, D. S., \& Wright, M. (Eds.). (2015). The Chicago Handbook of University technology transfer and academic entrepreneurship. University of Chicago Press.

Malecki, E. J. (2018). Entrepreneurship and entrepreneurial ecosystems. Geography. Compass, 12, e12359.

Malmberg, A., \& Maskell, P. (2006). Localized learning revisited. Growth and Change, 37(1), 1-18.

Melancon, Y., \& Doloreux, D. (2013). Developing a knowledge infrastructure to foster regional innovation in the periphery: A study from Quebec's Coastal Region in Canada. Regional Studies, 47(9), 1555-1572.

Menzel, M.-P. (2015). Interrelating dynamic proximities by bridging, reducing and producing distances. Regional Studies, 49(11), 1892-1907.

Mukhija, V. (2010). N of one plus some: An alternative strategy for conducting single case research. Journal of Planning Education and Research, 29(4), 416-426.

Nieth, L., Benneworth, P., Charles, D., Fonseca, L., Rodrigues, C., Salomaa, M., \& Stienstra, M. (2018). Embedding entrepreneurial regional innovation ecosystems: Reflecting on the role of effectual entrepreneurial discovery processes. European Planning Studies, 26(11), 2147-2166.

Perkmann, M., Tartari, V., McKelvey, M., Autio, E., Broström, A., D’Este, P., Fini, R., Geuna, A., Grimaldi, R., Hughes, A., Krabel, S., Kitson, M., Llerena, P., Lissoni, F., Salter, A., \& Sobrero, M. (2013). Academic engagement and commercialization: A review of the literature on universityindustry relations. Research Policy, 42, 423-442.

Petruzzelli, A. M. (2011). The impact of technological relatedness, priorties, and geographical distance on university-industry collaborations: A joint-patent analysis. Technovation, 31, 309-319.

Pfister, C., Koomen, M., Harhoff, D., \& Backes-Gellner, U. (2021). Regional innovation effects of applied research institutions. Research Policy, 50, 104197.

Ponds, R., van Oort, F., \& Frenken, K. (2007). The geographical and institutional proximity of research collaboration. Papers in Regional Science, 86(3), 423-444.

Rallet, A., \& Torre, A. (1999). Is geographical proximity necessary in the innovation networks in the era of global economy? GeoJournal, 49, 373-380.

Ranga, M., \& Etzkowitz, H. (2013). Triple Helix systems: An analytical framework for innovation policy and practice in the Knowledge Society. Industry and Higher Education, 27(3), 237-262.

Rossi, F., \& Goglio, V. (2020). Satellite university campuses and economic development in peripheral regions. Studies in Higher Education, 45(1), 34-54.

Shams, F., \& Huisman, J. (2016). The role of institutional dual embeddedness in the strategic local adaptation of international branch campuses: Evidence from Malaysia and Singapore. Studies in Higher Education, 41(6), 955-970.

Shapira, P. (2001). US manufacturing extension partnerships: Technology policy reinvented? Research Policy, 30, 977-992.

Siegel, D. S., Waldman, D. A., Atwater, L. E., \& Link, A. N. (2003). Commercial knowledge transfers from universities to firms: Improving the effectiveness of university-industry collaboration. Journal of High Technology Management Research, 14, 111-133.

Spigel, B. (2017). The relational organization of entrepreneurial ecosystems. Entrepreneurship Theory and Practice, 41(1), 49-72.

Steinmo, M., \& Rasmussen, E. (2016). How firms collaborate with public research organizations: The evolution of proximity dimensions in successful innovation projects. Journal of Business Research, 69, 1250-1259.

Stojcic, N. (2021). Collaborative innovation in emerging innovation systems: Evidence from Central and Eastern Europe. Journal of Technology Transfer, 46, 531-562.

Storz, C., ten Brink, T., \& Zou, N. (2021). Innovation in emerging economies: How do university-industry linkages and public procurement matter for small businesses? Asia Pacific Journal of Management. https://doi.org/10.1007/s10490-021-09763-z

Tanner, A. N. (2018). Changing locus of innovation: A micro-process approach on the dynamics of proximity. European Planning Studies, 26(12), 2304-2322.

Tödtling, F., \& Trippl, M. (2005). One size fits all? Towards a differentiated regional innovation policy approach. Research Policy, 34, 1203-1219. 
Torre, A., \& Gilly, J.-P. (2000). On the analytical dimension of proximity dynamics. Regional Studies, 34(2), 169-180.

Torre, A., \& Rallet, A. (2005). Proximity and localization. Regional Studies, 39(1), 47-59.

Trippl, M., Grillitsch, M., \& Isaksen, A. (2018). Exogenous sources of regional industrial change: Attraction and absorption of non-local knowledge for new path development. Progress in Human Geography, 42(5), 687-705.

Uyarra, E. (2010). Conceptualizing the Regional roles of universities, implications and contradictions. European Planning Studies, 18(8), 1227-1246.

Villani, E., Rasmussen, E., \& Grimaldi, R. (2017). How intermediary organizations facilitate university-industry technology transfer: A proximity approach. Technological Forecasting and Social Change, 114, 86-102.

Wright, M., Clarysse, B., Lockett, A., \& Knockaert, M. (2008). Mid-range universities' linkages with industry: Knowledge types and the role of intermediaries. Research Policy, 37, 1205-1123.

Wright, M., Siegel, D. S., \& Mustar, P. (2017). An emerging ecosystem for student start-ups. Journal of Technology Transfer, 42, 909-922.

Yamamura, S., \& Lasalle, P. (2020). Proximities and the emergence of regional industry: Evidence of the liability of smallness in Malta. European Planning Studies, 28(2), 380-399.

Yigitcanlar, T., Edvardsson, I. R., Johannesson, H., Kamruzzaman, M., Ioppolo, G., \& Pancholi, S. (2017). Knowledge-based development dynamics in less favoured regions: insights from Australian and Icelandic university towns. European Planning Studies, 25(12), 2272-2292.

Yin, R. K. (2018). Case study research and applications (6th ed.). Sage.

Youtie, J., \& Shapira, P. (2008). Building an innovation hub: A case study of the transformation of university roles in regional technological and economic development. Research Policy, 37, $1188-1204$.

Yusuf, S. (2008). Intermediating knowledge exchange between universities and businesses. Research Policy, 37(8), 1167-1174.

Zeng, X. X., Zhang, W. L., \& Hu, P. P. (2018). 40 Years of development of technological innovation in Guangdong (in Chinese). Sun Yat-sen University Press.

Zouain, D. M., Damiao, D., \& Catharino, M. (2007). The science and technology parks as instruments of public policies for promote the collaboration of technology based companies. In PICMET '07-2007 Portland international conference on management of engineering and technology (pp. 344-350).

Zukauskaite, E., Trippl, M., \& Plechero, M. (2017). Institutional thickness revisited. Economic Geography, 93(4), 325-345.

Publisher's Note Springer Nature remains neutral with regard to jurisdictional claims in published maps and institutional affiliations.

\section{Authors and Affiliations}

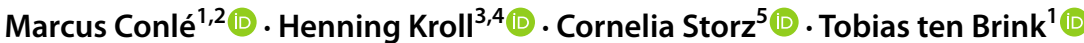

Henning Kroll

henning.kroll@isi.fraunhofer.de

Cornelia Storz

storz@wiwi.uni-frankfurt.de

Tobias ten Brink

t.tenbrink@jacobs-university.de

1 Social Sciences and Humanities, Jacobs University Bremen, Research IV, Campus Ring 1, 28759 Bremen, Germany

2 GIGA Institute for Asian Studies, German Institute for Global and Area Studies, Rothenbaumchaussee 32, 20148 Hamburg, Germany

3 Fraunhofer Institute for Systems and Innovation Research ISI, Breslauer Str. 48, 76139 Karlsruhe, Germany 
4 Institute of Economic and Cultural Geography, Leibniz University Hannover, Schneiderberg 50, 30167 Hannover, Germany

5 Faculty of Economics and Business, Goethe University Frankfurt, Theodor-W.-Adorno-Platz 4, 60323 Frankfurt am Main, Germany 